\title{
Inferring Policy Objectives from Economic Outcomes*
}

\author{
Richard Dennis $^{\dagger}$ \\ Federal Reserve Bank of San Francisco
}

This version June, 2003

First version March, 2003

\begin{abstract}
This paper stresses that estimated policy rules are reduced form equations that are silent on many important policy questions. To obtain a structural understanding of monetary policy it is necessary to estimate the policymaker's objective function, rather than its policy reaction function. With these issues in mind, this paper proposes a system-based estimation approach that uses the solution to the policymaker's optimization problem to infer the underlying policy regime from the economy's evolution over time. The paper derives conditions under which the parameters in a policymaker's policy objective function can be identified and estimated. These identification conditions apply to forwardlooking rational-expectations models as well as to backward-looking models, extending existing results. We apply these conditions to a New Keynesian stickyprice model of the US economy, estimating jointly all of the model's behavioral parameters and the policy regime parameters. The results show that the implicit inflation target and the relative weight placed on interest rate smoothing both declined with Volcker's appointment to Federal Reserve chairman. However, the estimates reveal that other - non-monetary-policy - parameters have changed over time also.

Keywords: Inflation Targeting, Time-consistent Policy, Policy Regime Change, Policy Preferences.
\end{abstract}

JEL Classification: E52, E58, C32, C61.

\footnotetext{
${ }^{*}$ I would like to thank seminar participants at the Bank of Canada for comments. The views expressed in this paper do not necessarily reflect those of the Federal Reserve Bank of San Francisco or the Federal Reserve System.

$\dagger$ Address for Correspondence: Economic Research, Mail Stop 1130, Federal Reserve Bank of San Francisco, 101 Market St, CA 94105, USA. Email: richard.dennis@sf.frb.org.
} 


\section{Introduction}

Taylor's (1993) study into US monetary policy sparked renewed interest in modeling monetary policy using state-contingent rules. Since then a literature has developed that uses estimated rules to summarize the systematic component to monetary policy. Studies that estimate the systematic component to monetary policy using Taylortype rules typically use a short term nominal interest rate as the policy instrument, with the rules themselves expressed either as state-contingent rules (Dennis, 2003; Levin, Wieland, and Williams, 1999) or as forward-looking rules (Batini and Haldane, 1999; Clarida, Galí, and Gertler, 2000). Monetary policy shocks, the non-systematic component to monetary policy, are typically analyzed using vector autoregressive models (Sims and Zha, 2001).

Some interesting stylized facts have emerged from the literature on estimated policy rules. One such fact is that lagged interest rates are invariably needed as regressors to adequately account for how nominal interest rates move over time, suggesting that central banks smooth interest rates (Clarida, et al. 2000). Furthermore, policy rules estimated over different sample periods seem to indicate that monetary policy in the US has undergone a significant change, with a more "activist" approach to policy taken after the mid-1980s ${ }^{1}$ than was pursued during the 1970s (Clarida, et al. 2000; McCallum, 2000). Indeed, the view that monetary policy was insufficiently activist during the 1970s is one popular explanation for the high inflation rates observed during that decade.

However, estimated policy rules cannot address many interesting and important policy issues. For instance, a valuable check on the credibility of an inflation targeting central bank would be to compare the inflation target that enters the objective function, the implicit inflation target, with the announced inflation target. Any significant discrepancy between the implicit target and the announced target would indicate a lack of commitment to the announced target. Similarly, recursive estimates of the implicit target that converged on the announced target would show that policy credibility is growing over time. For central banks like the US Federal Reserve, which are not explicit inflation targeters, but are required to maintain a

\footnotetext{
${ }^{1}$ Here, "activist" refers to the fact that interest rates move more than one-for-one with expected future inflation.
} 
nominal anchor, it is still pertinent to estimate the implicit inflation target, and to examine whether this target has changed over time. Yet, despite its obvious importance, estimates of a central banks' implicit inflation target cannot be obtained from estimated policy rules. The confounding factor is that even though the intercept in conventionally formulated policy rules is a function of the implicit inflation target, this critical parameter is not identified.

Other important issues, such as whether a policy regime change has occurred, also cannot be convincingly answered using estimated policy rules. Even if structural breaks are observed in a policy rule's feedback parameters these breaks cannot be unambiguously attributed to a regime change; they may reflect structural changes in the equations that constrain the policy process. The essential point here is that estimated policy rules are reduced-form equations that, because they are formulated, estimated, analyzed, and interpreted in the absence of a fully specified economic model, are uninformative of any policy issue that involves structural parameters or that requires a structural interpretation. To reveal what central banks aim to achieve through their policy actions it is necessary to recognize that central banks behave purposefully when setting policy and to explicitly model the central bank's optimization problem. Only through estimating a central bank's policy objective function, rather than its decision rule, is it possible to cast light on its objectives and preferences. Once the policy objective function parameters have been estimated, formal statistical tests of hypotheses, such as whether central bank's smooth interest rates or whether a policy regime change has occurred, become possible. ${ }^{2}$

The need to understand monetary policy at the level of targets and preferences has

\footnotetext{
${ }^{2}$ More to this point, that the distinction between the parameters in the policy rule and those in the policy objective function is critical is exemplified in the debate over whether central banks smooth interest rates. Estimated policy rules invariably include lagged interest rates as explanatory variables. Their presence is widely ascribed to the tendency for central banks to smooth interest rates. Rudebusch (2002a), however, argues that central banks do not smooth interest rates and that what is erroneously perceived as interest rate smoothing is simply the dynamic consequences of serially correlated policy shocks. Rudebusch contends that policy rules do not permit a direct test of the two hypotheses, but that the serially correlated policy shocks hypothesis is more consistent with term structure evidence. English, Nelson, and Sack (2003) challenge Rudebusch's claim that a direct test is not possible. They estimate a policy rule for the US, perform such a test, and show that lagged interest rates have significant explanatory power even after allowance is made for serially correlated shocks. What this debate overlooks is that whether central banks smooth interest rates or not should be framed as an hypothesis about the central bank's objective function, not as an hypothesis about the variables entering its policy rule.
} 
produced a small literature that estimates the parameters in central bank objective functions. This literature has tended to focus on the US and to concentrate on models in which private agents (but not the central bank) are backward-looking. For example, Salemi (1995) assumes that the constraints facing the US Federal Reserve can be modeled as a vector autoregression, while Dennis (2001b), Collins and Siklos (2001), and Favero and Rovelli (2003) all model the private sector using variants of the Rudebusch and Svensson (1999) model. However, a criticism often leveled at models in which private agents are backward-looking is that they are subject to the Lucas critique (Lucas, 1976). While empirical tests showing no evidence of parameter instability should go some way toward addressing this criticism, it is more attractive to explicitly model households and firms as forward-looking agents. But allowing private agents to be forward-looking raises considerable complications for estimation, primarily because it becomes necessary to model the strategic interactions that occur between the economic agents in the model. For this reason very few studies have attempted to estimate policy regime parameters from forward-looking models, and those that have gone down this path (Söderlind, Söderström, and Vredin, 2002; Castelnuovo, 2003) have resorted to informal calibration rather than using estimation. The exception is Salemi (2001) who assumes that the Federal Reserve can precommit to an optimized Taylor-type rule, thereby bypassing strategic considerations.

This paper constructs a forward-looking model, estimates it, and then uses it to address the issues raised above. The model that we analyze has explicit microfoundations and, consequently, its parameters relate to preferences and technology and can be readily interpreted; in this respect the model is very different to the models examined in previous studies. Before estimating the model, we first derive necessary and sufficient conditions for its parameters to be identified. These conditions are presented in terms of familiar rank and order conditions and are more general than those developed in Chow (1981), who only considered models with backward-looking private-agents. This paper also develops an estimation approach that allows all of the parameters in the model to be estimated jointly, while permitting the central bank's objective function to have an infinite horizon. Unlike other approaches, the estimation method employed here readily accommodates forward-looking agents. Moreover, the method does not require that the central bank's policy horizon be 
arbitrarily truncated in order to obtain an estimable Euler equation (c.f. Favero and Rovelli, 2003). Taking our model to the data, we obtain estimates of the Federal Reserve's policy objective function, including its implicit inflation target, and are able to formally examine the hypotheses that US monetary policy underwent a significant regime change in the early 1980s and that the Federal Reserve smooths interest rates.

The remainder of this paper is structured as follows. In the following section we introduce the central bank's optimization problem, providing general expressions for the objective function and the optimization constraints. Section 2 also describes how to solve for the economy's time-consistent equilibrium. Section 3 turns to econometric identification, deriving necessary and sufficient conditions for the parameters in the optimization constraints and those in the policy objective function to be identified. Section 4 presents a method by which the model's structural parameters can be estimated. The main difficulty here is to transform the system's decision rules and transition equations into a form suitable for estimation while at the same time overcoming the stochastic singularity that arises from the presence of identities. The New Keynesian sticky-price model that is estimated is constructed in section 5. After showing that the parameters in this model are identified, we estimate them using the approach developed in section 4 . The results are related to those obtained in previous studies. Section 6 concludes.

\section{The Theoretical Framework}

This section describes the central bank's optimization problem, introducing the policy objective function and the behavioral equations that constrain the optimization process. While the state-space form could be used, here the optimization constraints are written in structural form because this form allows us to quickly set up and solve the system for its time-consistent equilibrium. In addition, working with the constraints in structural form makes it easier to solve the central bank's dynamic optimization problem while at the same time estimating the model's behavioral parameters. The algorithm used to solve for the time-consistent equilibrium is developed and discussed in Dennis (2001a). 


\subsection{The Policy Objective Function}

Let $\mathbf{z}_{t}$ be an $n \times 1$ vector of endogenous variables and $\mathbf{x}_{t}$ be a $p \times 1$ vector of (independent) policy instruments. At this stage every variable in $\mathbf{z}_{t}$ and $\mathbf{x}_{t}$ is treated as a potential target variable. The target vectors for $\mathbf{z}_{t}$ and $\mathbf{x}_{t}$ are denoted $\overline{\mathbf{z}}$ and $\overline{\mathbf{x}}$, respectively. The policy objective function is assumed to be

$$
\begin{aligned}
\text { Loss } & =E_{t} \sum_{j=0}^{\infty} \beta^{j}\left[\left(\mathbf{z}_{t+j}-\overline{\mathbf{z}}\right)^{\prime} \mathbf{W}\left(\mathbf{z}_{t+j}-\overline{\mathbf{z}}\right)+\left(\mathbf{x}_{t+j}-\overline{\mathbf{x}}\right)^{\prime} \mathbf{Q}\left(\mathbf{x}_{t+j}-\overline{\mathbf{x}}\right)\right] \\
& \equiv E_{t} \sum_{j=0}^{\infty} \beta^{j}\left[\widehat{\mathbf{z}}_{t+j}^{\prime} \mathbf{W} \widehat{\mathbf{z}}_{t+j}+\widehat{\mathbf{x}}_{t+j}^{\prime} \mathbf{Q} \widehat{\mathbf{x}}_{t+j}\right]
\end{aligned}
$$

where $0<\beta<1$, where $\mathbf{W}(n \times n)$ and $\mathbf{Q}(p \times p)$ are square, symmetric, matrices containing policy preference parameters, or weights, where $E_{t}$ is the mathematical expectations operator conditional upon period $t$ information, and where $\widehat{\mathbf{z}}_{t} \equiv \mathbf{z}_{t}-\overline{\mathbf{z}}$ and $\widehat{\mathbf{x}}_{t} \equiv \mathbf{x}_{t}-\overline{\mathbf{x}}$. Equation (2) is highly attractive from a computational perspective because, with linear constraints, it leads to linear decision rules. Moreover, equation

(2) can be derived as a second-order approximation to a representative agent's utility function (Díaz-Giménez, 1999) and objective functions with this form are widely used in the literature. However, it is not necessary to interpret equation (2) as an approximation to a representative agent's utility function. Equation (2) can be motivated on political economy grounds (Cukierman, 1986) or on the basis that it is desirable to appoint a central banker who is more conservative than society as a whole (Rogoff, 1985). The latter implies that even if the central bank's goal is to maximize the representative agent's welfare the parameters in the central bank's objective function should differ from those implied by a second-order utility approximation. It is not necessary for either $\mathbf{W}$ or $\mathbf{Q}$ to have full rank. However, because the policy objective function is defined only up to an affine transformation, without loss of generality, we impose the normalization that $\operatorname{tr}(\mathbf{W})=1$.

\subsection{The Optimization Constraints and the Time-Consistent Solu- tion}

The central bank's problem is to choose $\mathbf{x}_{t}$ to minimize equation (2) subject to a system of dynamic constraints. These constraints consist of Euler equations associated 
with the private sectors' optimization problems and equations reflecting resource constraints, production technology, etc. As mentioned above, because we are interested in identifying and estimating the economy's structural parameters, it is desirable to formulate the central bank's optimization problem with the optimization constraints written in (second-order) structural form, rather than in state-space form. The optimization constraints are

$$
\mathbf{A}_{0} \mathbf{z}_{t}=\mathbf{a}+\mathbf{A}_{1} \mathbf{z}_{t-1}+\mathbf{A}_{2} E_{t} \mathbf{z}_{t+1}+\mathbf{A}_{3} \mathbf{x}_{t}+\mathbf{u}_{t}
$$

where $\mathbf{u}_{t} \sim \operatorname{iid}(\mathbf{0}, \boldsymbol{\Sigma})$ is an $n_{s} \times 1\left(n_{s} \leq n\right)$ vector of shocks, and where the model's structural parameters are contained in the $(n \times n)$ matrices $\mathbf{A}_{0}, \mathbf{A}_{1}$, and $\mathbf{A}_{2}$, in the $(n \times p)$ matrix $\mathbf{A}_{3}$, and in the $(n \times 1)$ constant vector $\mathbf{a}$. Without loss of generality, $\mathbf{A}_{0}$ is assumed to have full rank. The variance-covariance matrix of the shocks, $\boldsymbol{\Sigma}$, may be singular. We seek to identify and subsequently estimate the parameters in the structural model, $\mathbf{A}_{0}, \mathbf{a}, \mathbf{A}_{1}, \mathbf{A}_{2}$, and $\mathbf{A}_{3}$, jointly with the policy regime parameters, $\mathbf{W}, \mathbf{Q}, \overline{\mathbf{x}}$, and $\overline{\mathbf{z}}$.

To solve for the time-consistent equilibrium, it is convenient to rewrite equation (3) in terms of deviations from target values, as follows

$$
\mathbf{A}_{0} \widehat{\mathbf{z}}_{t}=\mathbf{A}_{1} \widehat{\mathbf{z}}_{t-1}+\mathbf{A}_{2} E_{t} \widehat{\mathbf{z}}_{t+1}+\mathbf{A}_{3} \widehat{\mathbf{x}}_{t}+\mathbf{u}_{t}
$$

where the intercepts in equation (3) have been eliminated by the requirement that

$$
\mathbf{a}+\mathbf{A}_{3} \overline{\mathbf{x}}+\left(\mathbf{A}_{1}+\mathbf{A}_{2}-\mathbf{A}_{0}\right) \overline{\mathbf{z}}=\mathbf{0} .
$$

Equation (5) must hold if the target vectors $\overline{\mathbf{z}}$ and $\overline{\mathbf{x}}$ are to be consistent with the structural model's nonstochastic steady-state. The numerical algorithms developed in Dennis (2001a) can be applied directly to equations (2) and (4) to solve for the time-consistent equilibrium. Taking the resulting solution and transforming back into levels (from deviations from targets) the system evolves according to

$$
\begin{aligned}
& \mathbf{z}_{t}=\mathbf{h}+\mathbf{H}_{1} \mathbf{z}_{t-1}+\mathbf{H}_{2} \mathbf{u}_{t}, \\
& \mathbf{x}_{t}=\mathbf{f}+\mathbf{F}_{1} \mathbf{z}_{t-1}+\mathbf{F}_{2} \mathbf{u}_{t}
\end{aligned}
$$

where

$$
\begin{aligned}
\mathbf{M} & =\mathbf{W}+\boldsymbol{\beta} \mathbf{F}_{1}^{\prime} \mathbf{Q} \mathbf{F}_{1}+\boldsymbol{\beta} \mathbf{H}_{1}^{\prime} \mathbf{M} \mathbf{H}_{1}, \\
\mathbf{D} & =\mathbf{A}_{0}-\mathbf{A}_{2} \mathbf{H}_{1},
\end{aligned}
$$


where the policy rule parameters are the solution to

$$
\begin{aligned}
\mathbf{F}_{1} & =-\left[\mathbf{A}_{3}^{\prime}\left(\mathbf{D}^{\prime}\right)^{-1} \mathbf{M D}^{-1} \mathbf{A}_{3}\right]^{-1} \mathbf{A}_{3}^{\prime}\left(\mathbf{D}^{\prime}\right)^{-1} \mathbf{M D}^{-1} \mathbf{A}_{1} \\
\mathbf{F}_{2} & =-\left[\mathbf{A}_{3}^{\prime}\left(\mathbf{D}^{\prime}\right)^{-1} \mathbf{M D}^{-1} \mathbf{A}_{3}\right]^{-1} \mathbf{A}_{3}^{\prime}\left(\mathbf{D}^{\prime}\right)^{-1} \mathbf{M D}^{-1} \\
\mathbf{f} & =\overline{\mathbf{x}}-\mathbf{F}_{1} \overline{\mathbf{z}}
\end{aligned}
$$

and where the parameters in the recursive equilibrium law of motion are given by

$$
\begin{aligned}
\mathbf{H}_{1} & =\mathbf{D}^{-1}\left(\mathbf{A}_{1}+\mathbf{A}_{3} \mathbf{F}_{1}\right), \\
\mathbf{H}_{2} & =\mathbf{D}^{-1}\left(\mathbf{I}+\mathbf{A}_{3} \mathbf{F}_{2}\right), \\
\mathbf{h} & =\left(\mathbf{I}-\mathbf{H}_{1}\right) \overline{\mathbf{z}} .
\end{aligned}
$$

If $\mathbf{A}_{0}, \mathbf{a}, \mathbf{A}_{1}, \mathbf{A}_{2}, \mathbf{A}_{3}, \mathbf{W}, \mathbf{Q}, \overline{\mathbf{x}}$, and $\overline{\mathbf{z}}$ are known, then the time-consistent policy rule and the associated recursive equilibrium law of motion can be solved numerically by iterating over equations $(8)$ - (11), (13), (14) until a fixed-point is reached. ${ }^{3}$ However, in this paper we seek to answer the reverse question: If $\mathbf{h}, \mathbf{H}_{1}, \mathbf{H}_{2}, \mathbf{f}, \mathbf{F}_{1}$, and $\mathbf{F}_{2}$ are known, under what conditions can $\mathbf{A}_{0}, \mathbf{a}, \mathbf{A}_{1}, \mathbf{A}_{2}, \mathbf{A}_{3}, \mathbf{W}, \overline{\mathbf{x}}$, and $\overline{\mathbf{z}}$ be identified. And, given that these structural parameters are identifiable, how can they be efficiently estimated. The following section derives necessary and sufficient conditions for the model and policy regime parameters to be identified; section 4 shows how the system can be estimated.

\section{Identifying the System}

Before the parameters in the structural model and those in the policy objective function can be estimated they must first be identified. As we show below, the conditions for identification are non-standard because the structural equations embed forward-looking rational expectations and because the economic system is subject to control, both of which reflect departures from the standard simultaneous equations econometric framework. Pesaran (1988) considers identification in rational expectations models, but not in systems that are subject to control. Chow (1981) looks at

\footnotetext{
${ }^{3}$ The recursion in equation (8) can be easily and quickly solved using the doubling algorithm, or the closed form solution vec $(\mathbf{M})=\left[\mathbf{I}-\beta \mathbf{H}_{1}^{\prime} \otimes \mathbf{H}_{1}^{\prime}\right]^{-1} \operatorname{vec}\left(\mathbf{W}+\beta \mathbf{F}_{1}^{\prime} \mathbf{Q} \mathbf{F}_{1}\right)$ can be used.
} 
econometric identification in systems that are subject to control, but not for models containing forward-looking rational expectations. In this section, we allow for both features and derive necessary and sufficient conditions for the parameters in the optimization constraints and those in the objective function to be identified. The only parameter that is not explicitly treated is the discount factor, $\beta$. In what follows we assume that $\beta$ is known; in both real business cycle models and New Keynesian models $\beta$ is invariably imposed ex ante because it is extremely difficult to estimate precisely (Ireland, 1997).

Proposition one: A necessary and sufficient condition for $\overline{\mathbf{z}}$ and $\overline{\mathbf{x}}$ to be identified is that $\left|\mathbf{I}-\mathbf{H}_{1}\right| \neq 0$.

Proof: Writing equations (12) and (15) in matrix form gives

$$
\left[\begin{array}{cc}
\mathbf{I} & -\mathbf{F}_{1} \\
\mathbf{0} & \mathbf{I}-\mathbf{H}_{1}
\end{array}\right]\left[\begin{array}{c}
\overline{\mathbf{x}} \\
\overline{\mathbf{z}}
\end{array}\right]=\left[\begin{array}{c}
\mathbf{f} \\
\mathbf{h}
\end{array}\right] .
$$

Provided $\left|\mathbf{I}-\mathbf{H}_{1}\right| \neq 0,\left[\begin{array}{cc}\mathbf{I} & -\mathbf{F}_{1} \\ \mathbf{0} & \mathbf{I}-\mathbf{H}_{1}\end{array}\right]$ has full rank and can be inverted to uniquely define $\overline{\mathbf{x}}$ and $\overline{\mathbf{z}}$.

Proposition one exploits the fact that $\overline{\mathbf{z}}$ must be consistent with the system's nonstochastic steady-state if the optimal policy problem is to be well-posed. Once the target vector $\overline{\mathbf{z}}$ is identified the intercept in the policy rule identifies $\overline{\mathbf{x}}$.

Proposition two: Let $\mathbf{C} \equiv \mathbf{A}_{1}+\mathbf{A}_{3} \mathbf{F}_{1}, \mathbf{H} \equiv\left[\begin{array}{ccc}-\mathbf{C} & \mathbf{A}_{0} & -\mathbf{A}_{2}\end{array}\right]$, and $\boldsymbol{\Gamma} \equiv\left[\begin{array}{ccc}\mathbf{I} & \mathbf{H}_{1}^{\prime} & \mathbf{H}_{1}^{2^{\prime}}\end{array}\right]^{\prime}$. Let the parameters in the i'th row of $\mathbf{H}, \mathbf{h}_{i}(1 \times 3 n)$, be subject to $r_{i}$ linear inhomogeneous restrictions $\mathbf{h}_{i} \mathbf{R}_{i}=\mathbf{r}_{i}$, where $\mathbf{R}_{i}$ has dimensions $3 n \times r_{i}$ and $\mathbf{r}_{i}$ has dimension $r_{i} \times 1$, then a necessary condition for identifying $\mathbf{H}$ is $r_{i} \geq 2 n, \forall i \in[1, \ldots, n]$. A sufficient condition for $\mathbf{H}$ to be identified is $\operatorname{rank}\left[\begin{array}{ll}\boldsymbol{\Gamma} & \mathbf{R}_{i}\end{array}\right]=3 n, \forall i \in[1, \ldots, n]$.

Proof: The solution to the rational expectations problem requires that $\mathbf{H}_{1}$ satisfy the following matrix quadratic (see equation, 13)

$$
\mathbf{A}_{2} \mathbf{H}_{1}^{2}-\mathbf{A}_{0} \mathbf{H}_{1}+\left(\mathbf{A}_{1}+\mathbf{A}_{3} \mathbf{F}_{1}\right)=\mathbf{0},
$$

or equivalently

$$
\left[\begin{array}{lll}
-\mathbf{C} & \mathbf{A}_{0} & -\mathbf{A}_{2}
\end{array}\right]\left[\begin{array}{c}
\mathbf{I} \\
\mathbf{H}_{1} \\
\mathbf{H}_{1}^{2}
\end{array}\right]=\mathbf{0}
$$


where $\mathbf{C} \equiv \mathbf{A}_{1}+\mathbf{A}_{3} \mathbf{F}_{1}$. Now let $\mathbf{H} \equiv\left[\begin{array}{lll}-\mathbf{C} & \mathbf{A}_{0} & -\mathbf{A}_{2}\end{array}\right]$ and $\boldsymbol{\Gamma} \equiv\left[\begin{array}{lll}\mathbf{I} & \mathbf{H}_{1}^{\prime} & \mathbf{H}_{1}^{2^{\prime}}\end{array}\right]^{\prime}$, then equation (17) can be written as

$$
\mathbf{H \Gamma}=\mathbf{0} .
$$

The row vector $\mathbf{h}_{i}$ is subject to the linear inhomogeneous restrictions

$$
\mathbf{h}_{i} \mathbf{R}_{i}=\mathbf{r}_{i}
$$

Combining (18) with (19) produces

$$
\left[\mathbf{h}_{i}\right]\left[\begin{array}{ll}
\boldsymbol{\Gamma} & \mathbf{R}_{i}
\end{array}\right]=\left[\begin{array}{ll}
\mathbf{0} & \mathbf{r}_{i}
\end{array}\right]
$$

The dimensions of $\mathbf{h}_{i}, \boldsymbol{\Gamma}$, and $\mathbf{R}_{i}$ are $1 \times 3 n, 3 n \times n$, and $3 n \times r_{i}$, respectively. Accordingly, $\mathbf{h}_{i}$ contains $3 n$ parameters that are jointly subject to $n+r_{i}$ restrictions. The restrictions in equation (20) include the normalization restriction that arises when a dependent variable is chosen. Consequently, to identify $\mathbf{h}_{i}$ it is necessary that $r_{i} \geq 2 n$. For these linear inhomogeneous restrictions to be sufficient requires that $\left[\begin{array}{ll}\boldsymbol{\Gamma} & \mathbf{R}_{i}\end{array}\right]$ be such that $\operatorname{rank}\left[\begin{array}{ll}\boldsymbol{\Gamma} & \mathbf{R}_{i}\end{array}\right]=3 n$.

In a standard simultaneous equations system without rational expectations, identifying an equation requires that at least as many restrictions be imposed as there are endogenous variables $\left(r_{i} \geq n\right)$. With the rational expectations term present each equation contains an additional $n$ parameters that need to be identified, but the number of reduced form parameters available is unchanged. It follows directly - and intuitively - that $n$ additional restrictions are required to achieve identification.

Proposition three: Let $\mathbf{A} \equiv\left[\begin{array}{ll}\mathbf{A}_{1} & \mathbf{A}_{3}\end{array}\right], \mathbf{\Lambda} \equiv\left[\begin{array}{ll}\mathbf{I} & \mathbf{F}_{1}^{\prime}\end{array}\right]^{\prime}$, and let $\mathbf{C}$ be known. Let the i'th row of $\mathbf{A}, \mathbf{a}_{i}(1 \times(n+p))$, be subject to $r_{i}$ linear inhomogeneous restrictions, $\mathbf{a}_{i} \mathbf{R}_{i}=\mathbf{r}_{i}$, where $\mathbf{R}_{i}$ has dimensions $\left((n+p) \times r_{i}\right)$, then a necessary condition for identifying $\mathbf{A}$ is that $r_{i} \geq p, \forall i \in[1, \ldots, n]$. A sufficient condition for identifying $\mathbf{A}$ is that $\operatorname{rank}\left[\begin{array}{cc}\boldsymbol{\Lambda} & \mathbf{Q}_{i}\end{array}\right]=n+p, \forall i \in[1, \ldots, n]$.

Proof: Recall from above that $\mathbf{C} \equiv \mathbf{A}_{1}+\mathbf{A}_{3} \mathbf{F}_{1}$ or equivalently

$$
\mathbf{A} \mathbf{\Lambda}=\mathbf{C}
$$


where $\mathbf{A} \equiv\left[\begin{array}{ll}\mathbf{A}_{1} & \mathbf{A}_{3}\end{array}\right]$ and $\boldsymbol{\Lambda} \equiv\left[\begin{array}{ll}\mathbf{I} & \mathbf{F}_{1}^{\prime}\end{array}\right]^{\prime}$. By assumption, $\mathbf{C}$ is known. The elements in $\mathbf{A}$ are also subject to the following linear inhomogeneous restrictions

$$
\mathbf{a}_{i} \mathbf{R}_{i}=\mathbf{r}_{i}
$$

Combining equations (21) and (22) gives

$$
\mathbf{a}_{i}\left[\begin{array}{ll}
\Lambda & \mathbf{R}_{i}
\end{array}\right]=\left[\begin{array}{ll}
\mathbf{C}_{i} & \mathbf{r}_{i}
\end{array}\right]
$$

The dimensions of $\mathbf{a}_{i}, \boldsymbol{\Lambda}$, and $\mathbf{R}_{i}$ are $1 \times(n+p),(n+p) \times n$, and $(n+p) \times r_{i}$, respectively. Therefore, $\mathbf{a}_{i}$ contains $n+p$ parameters that are collectively subject to $n+r_{i}$ linear restrictions. Consequently, a necessary condition for $\mathbf{a}_{i}$ to be identified is that $r_{i} \geq p$. A sufficient condition for $\mathbf{A}$ to be identified is that $\operatorname{rank}\left[\begin{array}{ll}\boldsymbol{\Lambda} & \mathbf{R}_{i}\end{array}\right]=$ $n+p$.

The role of proposition three is to disentangle the elements in $\mathbf{A}_{3}$ from those in $\mathbf{A}_{1}$. The elements in these two matrices are intertwined because monetary policy is set as a function of the state vector. In words, proposition three states that a necessary condition for identification is that a restriction on the elements in $\mathbf{A}_{1}$ and $\mathbf{A}_{3}$ must be imposed for each policy instrument in the system. Clearly if a structural equation contains all state variables, then the coefficient in $\mathbf{A}_{3}$ associated with that policy instrument in that equation cannot be identified.

Thus far we have presented conditions that are necessary and sufficient to identify $\mathbf{A}_{0}, \mathbf{A}_{1}, \mathbf{A}_{2}$, and $\mathbf{A}_{3}$ in the optimization constraints and the target vectors $\overline{\mathbf{z}}$ and $\overline{\mathbf{x}}$ in the objective function. Provided that these conditions hold, equation (5) uniquely identifies a.

Proposition four: Let $\mathbf{W}$ and $\mathbf{Q}$ be subject to the linear inhomogeneous restrictions $[\mathbf{R}] \operatorname{vec}(\mathbf{W})=\mathbf{r}$ and $[\mathbf{S}] \operatorname{vec}(\mathbf{Q})=\mathbf{s}$, where $\mathbf{R}, \mathbf{S}, \mathbf{r}$, and $\mathbf{s}$, have dimensions $r \times n^{2}, s \times p^{2}, r \times 1$, and $s \times 1$, respectively. A necessary condition for $\mathbf{W}$ and $\mathbf{Q}$ to be identified is that $r+s \geq n^{2}+p^{2}-n p$. A sufficient condition for $\mathbf{W}$ and $\mathbf{Q}$ to be identified is that $\operatorname{rank}\left(\left[\begin{array}{cc}\mathbf{J}_{1} & \mathbf{J}_{2} \\ \mathbf{R} & \mathbf{0} \\ \mathbf{0} & \mathbf{S}\end{array}\right]\right)=n^{2}+p^{2}$, where $\mathbf{J}=\left[\begin{array}{ll}\mathbf{J}_{1} & \mathbf{J}_{2}\end{array}\right]$ is defined below. 
Proof: Equation (10) can be expressed as

$$
\begin{array}{r}
\mathbf{A}_{3}^{\prime}\left(\mathbf{D}^{\prime}\right)^{-1} \mathbf{M D}^{-1} \mathbf{A}_{3} \mathbf{F}_{1}+\mathbf{A}_{3}^{\prime}\left(\mathbf{D}^{\prime}\right)^{-1} \mathbf{M D}^{-1} \mathbf{A}_{1}=\mathbf{0} \\
\mathbf{A}_{3}^{\prime}\left(\mathbf{D}^{\prime}\right)^{-1} \mathbf{M D}^{-1} \mathbf{C}=\mathbf{0} \\
\mathbf{A}_{3}^{\prime}\left(\mathbf{D}^{\prime}\right)^{-1} \mathbf{M H}_{1}=\mathbf{0} .
\end{array}
$$

Because $\mathbf{D}$ has full rank, equation (26) and equation (8) imply that $\mathbf{M}$ is rank deficient with $\operatorname{rank}(\mathbf{M})=\operatorname{rank}\left(\mathbf{H}_{1}\right)-\operatorname{rank}\left(\mathbf{A}_{3}\right) \leq n-p$. If $\mathbf{H}_{1}$ has full rank then clearly each column of $\mathbf{M}$ is subject to $p$ restrictions and $n \times p$ elements in $\mathbf{M}$ are identified. Vectorizing equation (26) yields

$$
\left[\mathbf{H}_{1}^{\prime} \otimes \mathbf{A}_{3}^{\prime}\left(\mathbf{D}^{\prime}\right)^{-1}\right] \operatorname{vec}(\mathbf{M})=\operatorname{vec}(\mathbf{0}) .
$$

At the same time, vectorizing equation (8) and rearranging gives

$$
\left[\mathbf{I}-\beta\left(\mathbf{H}_{1}^{\prime} \otimes \mathbf{H}_{1}^{\prime}\right)\right] \operatorname{vec}(\mathbf{M})=\operatorname{vec}(\mathbf{W})+\beta\left(\mathbf{F}_{1}^{\prime} \otimes \mathbf{F}_{1}^{\prime}\right) \operatorname{vec}(\mathbf{Q}) .
$$

Finally, vec $(\mathbf{W})$ and $\operatorname{vec}(\mathbf{Q})$ are subject to the following linear inhomogeneous restrictions

$$
\begin{aligned}
{[\mathbf{R}] \operatorname{vec}(\mathbf{W}) } & =\mathbf{r} \\
{[\mathbf{S}] \operatorname{vec}(\mathbf{Q}) } & =\mathbf{s},
\end{aligned}
$$

where equations (29) and (30) include the restrictions implied by the fact that $\mathbf{W}$ and $\mathbf{Q}$ are symmetric, and the normalization restriction stemming from the condition that $\operatorname{tr}(\mathbf{W})=1$.

Equation (28) can be rewritten as

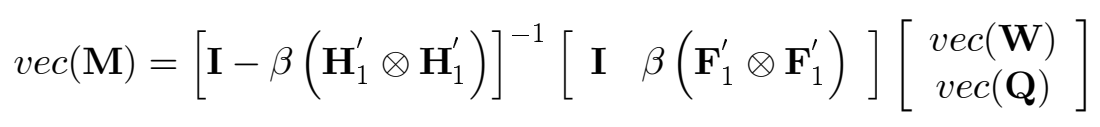

and combined with equation (27) to produce

$$
\left[\begin{array}{c}
\mathbf{H}_{1}^{\prime} \underset{\left(n p \times n^{2}\right)}{\otimes \mathbf{A}_{3}^{\prime} \mathbf{D}^{\prime}-1}
\end{array}\right]\left[\mathbf{I}-\beta \underset{\left(n^{2} \times n^{2}\right)}{\left(\mathbf{H}_{1}^{\prime} \otimes \mathbf{H}_{1}^{\prime}\right)}\right]^{-1}\left[\begin{array}{cc}
\mathbf{I} & \beta\left(\mathbf{F}_{1}^{\prime} \otimes \mathbf{F}_{1}^{\prime}\right) \\
& \left(n^{2} \times\left(n^{2}+p^{2}\right)\right)
\end{array}\right]\left[\begin{array}{c}
\operatorname{vec}(\mathbf{W}) \\
\operatorname{vec}(\mathbf{Q}) \\
\left(\left(n^{2}+p^{2}\right) \times 1\right)
\end{array}\right]=\underset{\left(\left(n^{2}+p^{2}\right) \times 1\right)}{\operatorname{vec}(\mathbf{0})},
$$


or in obvious notation as

$$
[\mathbf{J}]\left[\begin{array}{c}
\operatorname{vec}(\mathbf{W}) \\
\operatorname{vec}(\mathbf{Q})
\end{array}\right]=\operatorname{vec}(\mathbf{0})
$$

where $\mathbf{J}$ has dimensions $n p \times\left(n^{2}+p^{2}\right)$. Partitioning $\mathbf{J}$ into $[\mathbf{J}]=\left[\begin{array}{ll}\mathbf{J}_{1} & \mathbf{J}_{2}\end{array}\right]$, conformable with $\operatorname{vec}(\mathbf{W})$ and $\operatorname{vec}(\mathbf{Q})$, combining equation (33) with equations (29) and (30) yields

$$
\left[\begin{array}{cc}
\mathbf{J}_{1} & \mathbf{J}_{2} \\
\mathbf{R} & \mathbf{0} \\
\mathbf{0} & \mathbf{S}
\end{array}\right]\left[\begin{array}{c}
\operatorname{vec}(\mathbf{W}) \\
\operatorname{vec}(\mathbf{Q})
\end{array}\right]=\left[\begin{array}{c}
\operatorname{vec}(\mathbf{0}) \\
\mathbf{r} \\
\mathbf{s}
\end{array}\right]
$$

Given equation (34), a necessary condition for identification is that $r+s \geq n^{2}+p^{2}-n p$, while a sufficient condition for identification is that $\operatorname{rank}\left(\left[\begin{array}{cc}\mathbf{J}_{1} & \mathbf{J}_{2} \\ \mathbf{P} & \mathbf{0} \\ \mathbf{0} & \mathbf{K}\end{array}\right]\right)=n^{2}+p^{2}$.

As should be clear, proposition four extracts information from the policy rule feedback coefficients, $\mathbf{F}_{1}$, and uses this information to identify elements in the $\mathbf{W}$ and $\mathbf{Q}$ matrices. There are $n p$ feedback parameters in $\mathbf{F}_{1}$ and consequently at most $n p$ elements in $\mathbf{W}$ and $\mathbf{Q}$ can be identified from $\mathbf{F}_{1}$. Therefore, the order condition for identification can be restated more intuitively as saying that the number of free, or unconstrained, elements in $\mathbf{W}$ and $\mathbf{Q}$ must not exceed the number of feedback parameters in $\mathbf{F}_{1}$ (i.e., $n^{2}+p^{2}-r-s \leq n p$ ).

Finally, it is important to note that the identification conditions derived above do not utilize information contained in $\mathbf{F}_{2}$ or $\mathbf{H}_{2}$, although equations (9) and (14) show that $\mathbf{F}_{2}$ and $\mathbf{H}_{2}$ are informative of $\mathbf{A}_{0}$ and $\mathbf{A}_{3}$. We deliberately did not use $\mathbf{F}_{2}$ and $\mathbf{H}_{2}$ for identification because it allows us to derive conditions that also apply in the case where private agents form expectations using period $t-1$, rather than period $t$, information. Where expectations are formed using period $t-1$ information, equations (10) and (13) remain unchanged, but $\mathbf{F}_{2}=\mathbf{0}$ and $\mathbf{H}_{2}=\mathbf{I}$. As a consequence, the identification conditions derived above are unaffected by whether private agents form their expectations using period $t$ or period $t-1$ information.

\section{Estimating the System}

The previous section derived necessary and sufficient conditions for the parameters in the structural model - including the policy regime parameters - to be identified. 
In this section we assume that these conditions hold and show how the structural parameters, including the policy regime parameters, can be estimated. The approach we present involves estimating jointly all of the structural parameters in the system using FIML while imposing fully the cross-equation restrictions dictated by rational expectations and time-consistent policy.

The solution to the central bank's optimization problem yields first-order conditions that embed the central bank's policy objective parameters together with parameters from the economic environment in which policy is set. Solving these first-order conditions jointly with the optimization constraints generates decision rules for the agents in the economy - typically households, firms, and the central bank - and transition equations governing how the state variables evolve over time. Recovering information about the central bank's objective function then reduces to the problem of extracting information about policy from these decision rules and transition equations. Provided the relevant policy objective function parameters are identified, econometric techniques can, in principle, be applied to these equilibrium relationships to estimate the underlying policy regime parameters. ${ }^{4}$ Once the policy regime parameters have been estimated statistical tests can be performed on these parameters to determine whether the policy regime in operation has changed over time or whether policymakers seek to smooth interest rates.

To place the model in a form suitable for estimation some additional notation is necessary. Each endogenous variable in $\mathbf{z}_{t}$ is of one of two types: a stochastic endogenous variables, $\mathbf{z}_{t}^{s}$, or an endogenous variable defined by an identity, $\mathbf{z}_{t}^{i}$. Without loss of generality, assume that the elements in $\mathbf{z}_{t}$ have been ordered so that $\mathbf{z}_{t}=\left[\begin{array}{c}\mathbf{z}_{t}^{s} \\ \mathbf{z}_{t}^{i}\end{array}\right]$. With this variable ordering, equations (6) is

$$
\left[\begin{array}{c}
\mathbf{z}_{t}^{s} \\
\mathbf{z}_{t}^{i}
\end{array}\right]=\left[\begin{array}{c}
\mathbf{h}^{s} \\
\mathbf{h}^{i}
\end{array}\right]+\left[\begin{array}{ll}
\mathbf{H}_{1 a} & \mathbf{H}_{1 b} \\
\mathbf{H}_{1 c} & \mathbf{H}_{1 d}
\end{array}\right]\left[\begin{array}{c}
\mathbf{z}_{t-1}^{s} \\
\mathbf{z}_{t-1}^{i}
\end{array}\right]+\left[\begin{array}{c}
\mathbf{H}_{2 a} \\
\mathbf{H}_{2 b}
\end{array}\right]\left[\begin{array}{c}
\mathbf{u}_{t}^{s} \\
\mathbf{0}
\end{array}\right]
$$

and the policy rule (equation, 7) can be written as

$$
\mathbf{x}_{t}=\mathbf{f}+\mathbf{F}_{1 a} \mathbf{z}_{t-1}^{s}+\mathbf{F}_{1 b} \mathbf{z}_{t-1}^{i}+\mathbf{F}_{2 a} \mathbf{u}_{t}^{s} .
$$

\footnotetext{
${ }^{4}$ An alternative approach is to estimate the first-order conditions and the optimization constraints directly. However, working with the first order conditions is unsatisfactory because obtaining estimable first-order conditions requires arbitrarily restricting the central bank to have a finite - and typically short - policy horizon (see Favero and Rovelli, 2003, for an application of this approach).
} 
Let $\mathbf{G}$ be an $n_{s} \times n_{s}$ matrix, determined below, and apply it to equation (36) as follows

$$
\begin{aligned}
\mathbf{x}_{t}= & \mathbf{f}+\mathbf{F}_{1 a} \mathbf{z}_{t-1}^{s}+\mathbf{F}_{1 b} \mathbf{z}_{t-1}^{i}+\mathbf{F}_{2 a} \mathbf{u}_{t}^{s}+\mathbf{G} \mathbf{z}_{t}^{s}-\mathbf{G}_{t}^{s} \\
\mathbf{x}_{t}= & \mathbf{f}+\mathbf{F}_{1 a} \mathbf{z}_{t-1}^{s}+\mathbf{F}_{1 b} \mathbf{z}_{t-1}^{i}+\mathbf{F}_{2 a} \mathbf{u}_{t}^{s}+\mathbf{G} \mathbf{z}_{t}^{s} \\
& -\mathbf{G}\left(\mathbf{h}^{s}+\mathbf{H}_{1 a} \mathbf{z}_{t-1}^{s}+\mathbf{H}_{1 b} \mathbf{z}_{t-1}^{i}+\mathbf{H}_{2 a} \mathbf{u}_{t}^{s}\right) \\
\mathbf{x}_{t}= & \left(\mathbf{f}-\mathbf{G h}^{s}\right)+\left(\mathbf{F}_{1 a}-\mathbf{G H}_{1 a}\right) \mathbf{z}_{t-1}^{s}+\left(\mathbf{F}_{1 b}-\mathbf{G H}_{1 b}\right) \mathbf{z}_{t-1}^{i} \\
& +\left(\mathbf{F}_{2 a}-\mathbf{G H}_{2 a}\right) \mathbf{u}_{t}^{s}+\mathbf{G} \mathbf{z}_{t}^{s},
\end{aligned}
$$

then, provided $\mathbf{H}_{2 a}$ has full rank, ${ }^{5} \mathbf{G}$ is uniquely determined as the solution to $\mathbf{F}_{2 a}-$ $\mathbf{G H}_{2 a}=\mathbf{0}$ and equation (39) becomes

$$
\mathbf{x}_{t}=\left(\mathbf{f}-\mathbf{G h}^{s}\right)+\left(\mathbf{F}_{1 a}-\mathbf{G H}_{1 a}\right) \mathbf{z}_{t-1}^{s}+\left(\mathbf{F}_{1 b}-\mathbf{G H}_{1 b}\right) \mathbf{z}_{t-1}^{i}+\mathbf{G z}_{t}^{s} .
$$

Having eliminated the structural disturbances from the policy reaction function we now introduce an $n_{s} \times 1$ disturbance vector, $\mathbf{v}_{t}$, to the policy rule. This disturbance term represents measurement error and is motivated on the realistic and standard assumption that the econometrician estimating the system possesses less information than the policymaker (Hansen and Sargent, 1980). This disturbance term prevents a stochastic singularity from arising during estimation, facilitating estimation with likelihood-based methods.

Now, recall that the optimization constraints are as follows

$$
\begin{aligned}
\mathbf{A}_{0} \mathbf{z}_{t} & =\mathbf{a}+\mathbf{A}_{1} \mathbf{z}_{t-1}+\mathbf{A}_{2} E_{t} \mathbf{z}_{t+1}+\mathbf{A}_{3} \mathbf{x}_{t}+\mathbf{u}_{t} \\
\mathbf{A}_{0} \mathbf{z}_{t} & =\mathbf{a}+\mathbf{A}_{1} \mathbf{z}_{t-1}+\mathbf{A}_{2} \mathbf{H}_{1} \mathbf{z}_{t}+\mathbf{A}_{3} \mathbf{x}_{t}+\mathbf{u}_{t} \\
\left(\mathbf{A}_{0}-\mathbf{A}_{2} \mathbf{H}_{1}\right) \mathbf{z}_{t} & =\left(\mathbf{a}+\mathbf{A}_{2} \mathbf{h}\right)+\mathbf{A}_{1} \mathbf{z}_{t-1}+\mathbf{A}_{3} \mathbf{x}_{t}+\mathbf{u}_{t} .
\end{aligned}
$$

Partitioning $\mathbf{z}_{t}$ as earlier and defining $\mathbf{B}_{0} \equiv \mathbf{A}_{0}-\mathbf{A}_{2} \mathbf{H}, \mathbf{b} \equiv \mathbf{a}+\mathbf{A}_{2} \mathbf{h}, \mathbf{B}_{1} \equiv \mathbf{A}_{1}$, and

\footnotetext{
${ }^{5}$ If $\mathbf{H}_{2 a}$ is rank deficient, i.e., if $\operatorname{rank}\left(\mathbf{H}_{2 a}\right)=q<n_{s}$, then not all stochastic endogenous variables need to be included in equation (37) in order to eliminate the shocks from the policy rule. In this situation, multiple $\mathbf{G}$ matrices exists that annihilate the disturbance terms. While any $\mathbf{G}$ matrix that satisfies $\mathbf{F}_{2 a}-\mathbf{G H}_{2 a}=\mathbf{0}$ can, in principle, be used, in practice it is desirable to choose $\mathbf{G}$ such that its top $n_{s}-q$ rows (say) equal zero, and to use a $\mathbf{G}$ matrix with this form during all iterations of the FIML estimation.
} 
$\mathbf{B}_{3} \equiv \mathbf{A}_{3}$, equation (43) can be written as

$$
\begin{aligned}
{\left[\begin{array}{ll}
\mathbf{B}_{0 a} & \mathbf{B}_{0 b} \\
\mathbf{B}_{0 c} & \mathbf{B}_{0 d}
\end{array}\right]\left[\begin{array}{l}
\mathbf{z}_{t}^{s} \\
\mathbf{z}_{t}^{i}
\end{array}\right]=} & {\left[\begin{array}{l}
\mathbf{b}^{s} \\
\mathbf{b}^{i}
\end{array}\right]+\left[\begin{array}{ll}
\mathbf{B}_{1 a} & \mathbf{B}_{1 b} \\
\mathbf{B}_{1 c} & \mathbf{B}_{1 d}
\end{array}\right]\left[\begin{array}{l}
\mathbf{z}_{t-1}^{s} \\
\mathbf{z}_{t-1}^{i}
\end{array}\right] } \\
& +\left[\begin{array}{c}
\mathbf{B}_{3 a} \\
\mathbf{B}_{3 b}
\end{array}\right]\left[\mathbf{x}_{t}\right]+\left[\begin{array}{c}
\mathbf{u}_{t}^{s} \\
\mathbf{0}
\end{array}\right]
\end{aligned}
$$

Combining equation (40) with equation (44) gives

$$
\begin{gathered}
{\left[\begin{array}{ccc}
\mathbf{B}_{0 a} & -\mathbf{B}_{3 a} & \mathbf{B}_{0 b} \\
-\mathbf{G} & \mathbf{I} & \mathbf{0} \\
\mathbf{B}_{0 c} & -\mathbf{B}_{3 b} & \mathbf{B}_{0 d}
\end{array}\right]\left[\begin{array}{c}
\mathbf{z}_{t}^{s} \\
\mathbf{x}_{t} \\
\mathbf{z}_{t}^{i}
\end{array}\right]=\left[\begin{array}{c}
\mathbf{b}^{s} \\
\mathbf{f}-\mathbf{G h}^{s} \\
\mathbf{b}^{i}
\end{array}\right]} \\
+\left[\begin{array}{ccc}
\mathbf{B}_{1 a} & \mathbf{0} & \mathbf{B}_{1 b} \\
\mathbf{F}_{1 a}-\mathbf{G H}_{1 a} & \mathbf{0} & \mathbf{F}_{1 b}-\mathbf{G H}_{1 b} \\
\mathbf{B}_{1 c} & \mathbf{0} & \mathbf{B}_{1 d}
\end{array}\right]\left[\begin{array}{c}
\mathbf{z}_{t-1}^{s} \\
\mathbf{x}_{t-1} \\
\mathbf{z}_{t-1}^{i}
\end{array}\right]+\left[\begin{array}{c}
\mathbf{u}_{t}^{s} \\
\mathbf{v}_{t} \\
\mathbf{0}
\end{array}\right] .
\end{gathered}
$$

The next step is to substitute $\mathbf{z}_{t}^{i}$ from the system, producing equations for $\mathbf{z}_{t}^{s}$ and $\mathbf{x}_{t}$ that depend only on predetermined, observable, variables, i.e.,

$$
\begin{gathered}
{\left[\begin{array}{cc}
\mathbf{B}_{0 a}-\mathbf{B}_{0 b} \mathbf{B}_{0 d}^{-1} \mathbf{B}_{0 c} & \mathbf{B}_{0 b} \mathbf{B}_{0 d}^{-1} \mathbf{B}_{3 b}-\mathbf{B}_{3 a} \\
-\mathbf{G} & \mathbf{I}
\end{array}\right]\left[\begin{array}{c}
\mathbf{z}_{t}^{s} \\
\mathbf{x}_{t}
\end{array}\right]=\left[\begin{array}{c}
\mathbf{b}^{s}-\mathbf{B}_{0 b} \mathbf{B}_{0 d}^{-1} \mathbf{b}^{i} \\
\mathbf{f}-\mathbf{G h}^{s}
\end{array}\right]} \\
+\left[\begin{array}{cc}
\mathbf{B}_{1 a}-\mathbf{B}_{0 b} \mathbf{B}_{0 d}^{-1} \mathbf{B}_{1 c} & \mathbf{0} \\
\mathbf{F}_{1 a}-\mathbf{G H}_{1 a} & \mathbf{0}
\end{array}\right]\left[\begin{array}{c}
\mathbf{z}_{t-1}^{s} \\
\mathbf{x}_{t-1}
\end{array}\right]+\left[\begin{array}{c}
\mathbf{B}_{1 b}-\mathbf{B}_{0 b} \mathbf{B}_{0 d}^{-1} \mathbf{B}_{1 d} \\
\mathbf{F}_{1 b}-\mathbf{G} \mathbf{H}_{1 b}
\end{array}\right]\left[\mathbf{z}_{t-1}^{i}\right]+\left[\begin{array}{c}
\mathbf{u}_{t}^{s} \\
\mathbf{v}_{t}
\end{array}\right] .
\end{gathered}
$$

More compactly, equation (46) can be written as

$$
\mathbf{C}_{0} \mathbf{y}_{t}=\mathbf{c}+\mathbf{C}_{1} \mathbf{y}_{t-1}+\mathbf{C}_{2} \mathbf{z}_{t-1}^{i}+\boldsymbol{\epsilon}_{t},
$$

where $\mathbf{y}_{t} \equiv\left[\begin{array}{c}\mathbf{z}_{t}^{s} \\ \mathbf{x}_{t}\end{array}\right], \boldsymbol{\epsilon}_{t} \equiv\left[\begin{array}{c}\mathbf{u}_{t}^{s} \\ \mathbf{v}_{t}\end{array}\right]$, and the definitions of $\mathbf{C}_{0}, \mathbf{c}, \mathbf{C}_{1}$, and $\mathbf{C}_{2}$ are straightforward.

The model is now in a form to which likelihood-based estimation methods can be applied. Let $\boldsymbol{\theta}=\left\{\mathbf{A}_{0}, \mathbf{a}, \mathbf{A}_{1}, \mathbf{A}_{2}, \mathbf{A}_{3}, \mathbf{W}, \mathbf{Q}, \overline{\mathbf{x}}, \overline{\mathbf{z}}\right\}$ and assume that the initial conditions $\mathbf{y}_{1}$ are fixed, so that $P\left(\mathbf{y}_{1} \mid\left\{\mathbf{z}_{t}^{i}\right\}_{1}^{T} ; \boldsymbol{\theta}, \boldsymbol{\Phi}\right)$ is a proportionality constant, then the joint probability density function (PDF) for the data can be written as

$$
P\left(\left\{\mathbf{y}_{t}\right\}_{1}^{T} \mid\left\{\mathbf{z}_{t}^{i}\right\}_{1}^{T} ; \boldsymbol{\theta}, \boldsymbol{\Phi}\right) \propto P\left(\left\{\mathbf{y}_{t}\right\}_{2}^{T} \mid\left\{\mathbf{z}_{t}^{i}\right\}_{1}^{T}, \mathbf{y}_{1} ; \boldsymbol{\theta}, \boldsymbol{\Phi}\right)
$$

where $T$ is the sample size, including initial conditions. Next postulate that $\boldsymbol{\epsilon}_{t} \mid\left\{\mathbf{y}_{j-1}, \mathbf{z}_{j}^{i}\right\}_{1}^{t} \sim$ $N(0, \boldsymbol{\Phi}) \forall t$, then, from equation (47), the joint PDF for $\left\{\mathbf{y}_{t}\right\}_{1}^{T}$ conditional on $\left\{\mathbf{z}_{t}^{i}\right\}_{1}^{T}$ 
gives rise to a concentrated log-likelihood function that can be expressed as

$$
\begin{aligned}
\ln L_{c}\left(\boldsymbol{\theta} ;\left\{\mathbf{y}_{t}\right\}_{1}^{T} \mid\left\{\mathbf{z}_{t}^{i}\right\}_{1}^{T}\right) \propto & -\frac{\left(n_{s}+p\right)(T-1)}{2}[1+\ln (2 \pi)]+(T-1) \ln \left|\mathbf{C}_{0}\right| \\
& -\frac{\left(n_{s}+p\right)}{2} \ln |\widetilde{\boldsymbol{\Phi}}(\boldsymbol{\theta})|
\end{aligned}
$$

where

$$
\widetilde{\boldsymbol{\Phi}}(\boldsymbol{\theta})=\sum_{t=2}^{T} \frac{\widetilde{\boldsymbol{\epsilon}}_{t} \widetilde{\boldsymbol{\epsilon}}_{t}}{T-1} .
$$

The structural parameters, $\boldsymbol{\theta}$, can be estimated by maximizing equation (49) with an estimate of $\boldsymbol{\Phi}$ then recovered from equation (50). To perform inference, the variancecovariance matrix for $\widetilde{\boldsymbol{\theta}}$ can be constructed from inverting the Fisher-Information matrix, $H(\boldsymbol{\theta})=-E\left[\frac{\partial^{2} \ln L_{c}\left(\boldsymbol{\theta} ;\left\{\mathbf{y}_{t}\right\}_{1}^{T} \mid\left\{\mathbf{z}_{t}^{i}\right\}_{1}^{T}\right)}{\partial \boldsymbol{\theta} \partial \boldsymbol{\theta}^{\prime}}\right]$, from the BHHH outer-product variance estimator, $G(\boldsymbol{\theta})=E\left[\sum_{t=2}^{T}\left(\frac{\partial \ln L_{c}^{t}\left(\boldsymbol{\theta} ;\left\{\mathbf{y}_{j}\right\}_{t-1}^{t} \mid\left\{\mathbf{z}_{t}^{i}\right\}_{1}^{T}\right)}{\partial \theta} \frac{\partial \ln L_{c}^{t}\left(\boldsymbol{\theta} ;\left\{\mathbf{y}_{j}\right\}_{t-1}^{t} \mid\left\{\mathbf{z}_{t}^{i}\right\}_{1}^{T}\right)}{\partial \boldsymbol{\theta}^{\prime}}\right)\right]$, or from the robust-sandwich estimator (White, 1982), $\operatorname{Var}(\widetilde{\boldsymbol{\theta}})=[H(\boldsymbol{\theta})]^{-1}[G(\boldsymbol{\theta})][H(\boldsymbol{\theta})]^{-1}$, where $H(\boldsymbol{\theta})$ and $G(\boldsymbol{\theta})$ are evaluated at $\widetilde{\boldsymbol{\theta}}$ in each case.

\section{$5 \quad$ US Monetary Policy Objectives}

The model that we examine is a relatively simple business-cycle model with optimizing households and firms. We will use this model to investigate whether a monetary policy regime change occurred in the early 1980s and, if it did, to try to characterize the nature of the change in terms of policy preferences and targets. We will also formally test the null hypothesis that the US Federal Reserve does not smooth interest rates, basing the test on the policy preferences parameters rather than on the feedback parameters in a policy rule. However, before the model can be estimated and before any hypothesis tests can be performed, the structural parameters must be identified. Consequently, after presenting the model, we apply the conditions from in section 3 to show that the model is identified, then we take the model to the data and estimate the underlying monetary policy regime.

\subsection{The Model}

The model is derived in Appendix A. Briefly, however, households choose consumption, leisure, and their balances of nominal money and bonds to maximize their utility 
function, which exhibits internal habit formation in consumption. Firms are monopolistically competitive, hiring labor in a perfectly competitive market to produce their differentiated product. Prices are not perfectly flexible. Following Calvo (1983), each period a fixed proportion of firms re-optimize their price; firms that do not re-optimize are assumed to index their output price to last period's inflation rate (Christiano, Eichenbaum, and Evans, 2001). In log-linearized form, the model is

$$
\begin{aligned}
E_{t} \Delta \widehat{c}_{t+1} & =\frac{\gamma(\sigma-1)}{[\sigma+\gamma \beta(\sigma \gamma-1-\gamma)]}\left[\Delta \widehat{c}_{t}+\beta E_{t} \Delta \widehat{c}_{t+2}+\frac{1}{\gamma(\sigma-1)} E_{t}\left(\widehat{i}_{t}-\widehat{\pi}_{t+1}\right)\right] \\
& \equiv a_{1} \Delta \widehat{c}_{t}+\beta a_{1} E_{t} \Delta \widehat{c}_{t+2}+a_{2} E_{t}\left(\widehat{i}_{t}-\widehat{\pi}_{t+1}\right)+g_{t} \\
\widehat{\pi}_{t} & =\frac{1}{1+\beta} \widehat{\pi}_{t-1}+\frac{\beta}{1+\beta} E_{t} \widehat{\pi}_{t+1}+\frac{\left(1-\beta \xi_{p}\right)\left(1-\xi_{p}\right)}{(1+\beta) \xi_{p}} \widehat{c}_{t}+u_{t}
\end{aligned}
$$

where $c_{t}$ is consumption, $i_{t}$ is the nominal interest rate, $\pi_{t}$ is inflation, $g_{t}$ is a household preference shock, and $u_{t}$ is a transitory supply shock. As earlier, " $\widehat{z}$ ", for a generic variable $z$, denotes a deviation from target. Turning to the model's parameters, $\beta$ $(0 \leq \beta \leq 1)$ is the discount factor, $\gamma(0 \leq \gamma \leq 1)$ is the internal habit formation parameter, $\frac{1}{\sigma}(\sigma \geq 0)$ measures the curvature of the utility function with respect to consumption and is the intertemporal elasticity of substitution when $\gamma=0$, and $\xi_{p}\left(0 \leq \xi_{p} \leq 1\right)$ is the Calvo-pricing parameter $\left(1-\xi_{p}\right.$ is the proportion of firms that re-optimize their price each period). Using the fact that $\widehat{\pi}_{t}=\pi_{t}-\pi^{*}$ and $\widehat{i}_{t}=i_{t}-\rho^{*}-\pi^{*}$, equations (52) and (53) become

$$
\begin{aligned}
\widehat{c}_{t} & =p_{1} \widehat{c}_{t-1}+p_{2} E_{t} \widehat{c}_{t+1}+p_{3} E_{t} \widehat{c}_{t+2}-p_{4}\left(i_{t}-E_{t} \pi_{t+1}-\rho^{*}\right)-p_{5} g_{t} \\
\pi_{t} & =p_{6} \pi_{t-1}+p_{7} E_{t} \pi_{t+1}+p_{8} \widehat{c}_{t}+u_{t}
\end{aligned}
$$

where $p_{1}=\frac{a_{1}}{1+a_{1}}, p_{2}=\frac{\left(1-\beta a_{1}\right)}{1+a_{1}}, p_{3}=\left(1-p_{1}-p_{2}\right), p_{4}=\frac{a_{2}}{1+a_{1}}, p_{5}=\frac{1}{1+a_{1}}, p_{6}=$

$\frac{1}{1+\beta}, p_{7}=\left(1-p_{6}\right)$, and $p_{8}=\frac{\left(1-\beta \xi_{p}\right)\left(1-\xi_{p}\right)}{(1+\beta) \xi_{p}}$. In equation (54), $\rho^{*}$ can be interpreted as the equilibrium real interest rate (Laubach and Williams, 2003). The shocks, $g_{t}$ and $u_{t}$, are independent, zero-mean, finite-variance, white-noise processes.

\subsection{Identification}

The first point to note is that the identification conditions developed in section 3 apply to the parameters $p_{1}-p_{8}$, rather than to $\gamma, \sigma, \xi_{p}$, and $\beta$ directly. However, once $\beta$ is specified (we do not attempt to estimate this parameter), $\xi_{p}$ is identified 
from $p_{8}$ through the expression $\xi_{p}=\frac{\left[1+\beta+(1+\beta) p_{8}\right]}{2 \beta}-\frac{\sqrt{\left[1+\beta+(1+\beta) p_{8}\right]^{2}-4 \beta}}{2 \beta}$, where the negative root of the quadratic is the relevant root because the model requires that $p_{8}=0$ when $\xi_{p}=0$. In addition, $a_{1}$ and $a_{2}$ are uniquely identified from $p_{1}$ and $p_{4}$ $\left(a_{1}=\frac{p_{1}}{1-p_{1}}\right.$ and $\left.a_{2}=\frac{p_{4}}{1-p_{1}}\right)$, and once $a_{1}$ and $a_{2}$ are known values for $\gamma$ and $\sigma$ can be recovered. Specifically, $\gamma=\frac{1-a_{2}}{2 \beta\left(a_{1}-a_{2}\right)}+\frac{\sqrt{\left(a_{2}-1\right)^{2}-4 \beta\left(a_{1}-a_{2}\right) a_{1}}}{2 \beta\left(a_{1}-a_{2}\right)}$, where the positive root is relevant because the model implies that $a_{1}=0$ when $\gamma=0$, and $\sigma=1+\frac{a_{1}}{\gamma a_{2}}$. Our task in this section, then, is to identify $p_{1}, p_{4}, p_{8}$, and $\rho^{*}$, which parameterize the optimization constraints, and $\lambda, \nu$, and $\pi^{*}$, which parameterize the policy objective function $^{6}$

$$
\operatorname{Loss}(t, \infty)=E_{t} \sum_{j=0}^{\infty} \beta^{j}\left[\left(\pi_{t+j}-\pi^{*}\right)^{2}+\lambda \widehat{c}_{t+j}^{2}+\nu\left(\Delta i_{t+j}\right)^{2}\right],
$$

where $\lambda, \nu \geq 0$. To determine whether these structural parameters are identified we apply propositions one-through-four from section 3, focusing on the order (necessary) conditions because they are more readily verifiable than the rank (sufficient) conditions. Because we observe the system's reduced form, we know $\mathbf{h}$ and $\mathbf{H}_{1}$ in the recursive equilibrium law of motion

$$
\mathbf{z}_{t}=\mathbf{h}+\mathbf{H}_{1} \mathbf{z}_{t-1}+\mathbf{H}_{2} \mathbf{u}_{t}
$$

and $\mathbf{f}$ and $\mathbf{F}_{1}$ in the policy rule

$$
\mathbf{x}_{t}=\mathbf{f}+\mathbf{F}_{1} \mathbf{z}_{t-1}+\mathbf{F}_{2} \mathbf{u}_{t}
$$

The nature of the time-consistent solution is such that $\mathbf{z}_{t}$ is covariance stationary, which requires that the spectral radius of $\mathbf{H}_{1}$ be less than one. Because $\mathbf{H}_{1}$ does not have any eigenvalues on the unit sphere, $\left|\mathbf{I}-\mathbf{H}_{1}\right| \neq \mathbf{0}$, and hence from proposition one $\overline{\mathbf{z}}$ is identified from $\overline{\mathbf{z}}=\left(\mathbf{I}-\mathbf{H}_{1}\right)^{-1} \mathbf{h}$. Given $\overline{\mathbf{z}}, \overline{\mathbf{x}}$ is identified from $\overline{\mathbf{x}}=\mathbf{f}+\mathbf{F}_{1} \overline{\mathbf{z}}$. Next we use propositions two and three to identify $\mathbf{A}_{0}, \mathbf{A}_{1}, \mathbf{A}_{3}$, and $\mathbf{A}_{3}$, from which $\mathbf{a}$ is also identified, then we use proposition four to identify $\mathbf{W}$ and $\mathbf{Q}$.

Writing equations (54) and (55) in matrix form $\left(\mathbf{A}_{0} \mathbf{z}_{t}=\mathbf{a}+\mathbf{A}_{1} \mathbf{z}_{t-1}+\mathbf{A}_{2} E_{t} \mathbf{z}_{t+1}+\right.$

\footnotetext{
${ }^{6}$ Note that our empirical results do not impose the restriction $\operatorname{tr}(W)=1$. Instead, following the custom in the monetary policy rules literature, we normalize the weight on inflation to unity and express the remaining weights relative to that on inflation. The discount factor, $\beta$, is set to 0.99.
} 
$\mathbf{A}_{3} \mathbf{x}_{t}+\mathbf{u}_{t}$ ) we have

$$
\begin{gathered}
{\left[\begin{array}{ccccc}
1 & 0 & 0 & 0 & 0 \\
-p_{8} & 1 & 0 & 0 & 0 \\
0 & 0 & 1 & 0 & 0 \\
0 & 0 & 0 & 1 & 0 \\
0 & 0 & 0 & 0 & 1
\end{array}\right]\left[\begin{array}{c}
\widehat{c}_{t} \\
\pi_{t} \\
\widehat{c}_{t+1} \\
\Delta i_{t} \\
i_{t}
\end{array}\right]=\left[\begin{array}{c}
p_{4} \rho^{*} \\
0 \\
0 \\
0 \\
0
\end{array}\right]+\left[\begin{array}{ccccc}
-p_{1} & 0 & 0 & 0 & 0 \\
0 & p_{6} & 0 & 0 & 0 \\
0 & 0 & 0 & 0 & 0 \\
0 & 0 & 0 & 0 & -1 \\
0 & 0 & 0 & 0 & 0
\end{array}\right]\left[\begin{array}{c}
\widehat{c}_{t-1} \\
\pi_{t-1} \\
\widehat{c}_{t} \\
\Delta i_{t-1} \\
i_{t-1}
\end{array}\right]} \\
+\left[\begin{array}{ccccc}
p_{2} & p_{4} & p_{3} & 0 & 0 \\
0 & p_{7} & 0 & 0 & 0 \\
1 & 0 & 0 & 0 & 0 \\
0 & 0 & 0 & 0 & 0 \\
0 & 0 & 0 & 0 & 0
\end{array}\right] E_{t}\left[\begin{array}{c}
\widehat{c}_{t+1} \\
\pi_{t+1} \\
\widehat{c}_{t+2} \\
\Delta i_{t+1} \\
i_{t+1}
\end{array}\right]+\left[\begin{array}{c}
-p_{4} \\
0 \\
0 \\
1 \\
1
\end{array}\right]\left[\begin{array}{c}
-p_{5} g_{t} \\
u_{t} \\
0 \\
0 \\
0
\end{array}\right],
\end{gathered}
$$

where it is to the first two equations in this system that we direct our attention. ${ }^{7}$ Considering the consumption equation first, the matrices $\mathbf{C} \equiv \mathbf{A}_{1}+\mathbf{A}_{3} \mathbf{F}_{1}, \mathbf{A}_{0}$, and $\mathbf{A}_{2}$ are collectively subject to 10 restrictions. ${ }^{8}$ Thus, in terms of proposition two, $r=10$, which satisfies the requirement that $r \geq 2 n(n=5)$, and hence the order condition from proposition two holds. Similarly, for the Phillips curve the matrices $\mathbf{C} \equiv \mathbf{A}_{1}+\mathbf{A}_{3} \mathbf{F}_{1}, \mathbf{A}_{0}$, and $\mathbf{A}_{2}$ are collectively subject to 11 restrictions $(r=11){ }^{9}$ which is again greater than or equal to $2 n$, implying that the order condition of proposition two holds. Turning to proposition three, for the consumption equation there are four exclusion restrictions on $\mathbf{A}=\left[\begin{array}{ll}\mathbf{A}_{1} & \mathbf{A}_{3}\end{array}\right](r=4)$ and only one policy instrument $(p=1)$. Hence, the order condition $r \geq p$ is met. Similarly, for the Phillips curve, there are five exclusion restrictions on $\mathbf{A}$, so the necessary condition for proposition three to hold is satisfied.

Up to this point we have shown that the order conditions of propositions one three hold, from which it follows that the matrices $\mathbf{A}_{0}, \mathbf{A}_{1}, \mathbf{A}_{2}$, and $\mathbf{A}_{3}$ are identified as well as the policy targets, $\overline{\mathbf{z}}$ and $\overline{\mathbf{x}}$. Equation (5) can now be employed to identify the intercept vector, $\mathbf{a}$. It only remains to identify the policy preference matrices $\mathbf{W}$ and $\mathbf{Q}$. With the weight on inflation in $\mathbf{W}$ normalized to unity, there are only two free policy preference parameters in $\mathbf{W}$ and $\mathbf{Q}$, namely $\lambda$ and $\nu$. However, there

\footnotetext{
${ }^{7}$ The remaining rows in equation $(59)$ are identities that are automatically identified.

${ }^{8}$ These restrictions are a normalization restriction and four exclusion restrictions on $\mathbf{A}_{0}$, the restrictions that the elements in $\mathbf{C}$ associated with $c_{t}$ and $\Delta i_{t-1}$ equal zero, and two exclusion restrictions and the restriction that $p_{1}+p_{2}+p_{3}=0$ on $\mathbf{A}_{2}$.

${ }^{9}$ The restrictions on the Phillips curve are a normalization restriction and three exclusion restrictions on $\mathbf{A}_{0}$, the restrictions that the elements in $\mathbf{C}$ associated with $c_{t}$ and $\Delta i_{t-1}$ equal zero, and three exclusion restrictions and the restriction that $p_{7}=1-p_{6}$ on $\mathbf{A}_{2}$.
} 
are three non-trivial feedback parameters in $\mathbf{F}_{1}$, those on $\widehat{c}_{t-1}, \pi_{t-1}$, and $i_{t-1}$, from which it follows that the order condition in proposition four is met.

\subsection{A Comparison of Policy Regimes}

Equations (54) and (55), and the policy objective function, equation (56), are estimated over four sample periods. The cross-equation restrictions implied by rational expectations and those dictated by time-consistent policy are imposed. Within the objective function that is estimated an inflation stabilization goal is imposed, while an output stabilization goal, and an interest rate smoothing goal are allowed for. To estimate the model, $c_{t}=\log \left(\frac{Y_{t}}{Y_{t}^{p}}\right) \times 100$, where $Y_{t}$ is real GDP and $Y_{t}^{p}$ is the Congressional Budget Office measure of potential output, $\pi_{t}=\log \left(\frac{P_{t}}{P_{t-1}}\right) \times 400$, where $P_{t}$ is the GDP chain-weighted price index, and $i_{t}$ is the annualized quarterly federal funds rate. The (concentrated) log-likelihood function (equation, 49), is maximized using the BFGS algorithm and the standard errors for the parameter estimates are constructed using White's (1982) robust-sandwich estimator.

We first estimate the model over the full sample, which begins in 1966.Q1, from when the federal funds rate first traded consistently above the discount rate, and ends in 2002.Q2. Of course the monetary policy regime in operation may not have been constant over this entire period. For this reason we also estimate the model over 1966.Q1 - 1979.Q3, which covers the period prior to Volcker's appointment to Federal Reserve chairman, over 1983.Q1 - 2002.Q2, a period during which Volcker and then Greenspan were Federal Reserve chairmen, but excluding the non-borrowed reserves targeting episode in the early 1980s, and over 1987.Q3 - 2002.Q2, a period during which Greenspan has been chairman. We refer to these three sub-samples as the pre-Volcker period, the Volcker-Greenspan period, and the Greenspan period, respectively. We do not attempt to estimate the model for the Volcker period because the sample length is too short. ${ }^{10}$ However, by comparing the model estimates for the Volcker-Greenspan period with those for the Greenspan period we hope to infer something about the parameters that prevailed during the Volcker period.

Table 1 presents the estimation results. To interpret the results, note that for

\footnotetext{
${ }^{10}$ For the same reason we do not attempt to partition the pre-Volcker period according to the tenures of Martin, Burns, and Miller.
} 
the policy preference parameters a "0.00" indicates that the parameter was found to be constrained at its lower bound. Where parameters are subject to non-negativity constraints, the significance levels shown in Table 1 are for one-sided hypothesis tests.

\begin{tabular}{|c|c|c|c|c|c|c|c|c|}
\hline \multicolumn{9}{|c|}{ Table 1: Structural Model Estimates } \\
\hline & \multicolumn{2}{|c|}{ Full Sample } & \multicolumn{2}{|c|}{ Pre-Volcker } & \multicolumn{2}{|c|}{ Volcker-Greenspan } & \multicolumn{2}{|c|}{ Greenspan } \\
\hline Parameter & Est. & s.e. & Est. & s.e. & Est. & s.e. & Est. & s.e. \\
\hline$\rho^{*}$ & $2.60^{\dagger \dagger}$ & 0.93 & 1.74 & 1.21 & $2.37^{\ddagger}$ & 1.17 & $2.34^{\dagger \dagger}$ & 0.63 \\
\hline$\gamma$ & $1.04^{\dagger \dagger}$ & 0.13 & $1.08^{\dagger \dagger}$ & 0.24 & $1.02^{\dagger \dagger}$ & 0.16 & $1.02^{\dagger \dagger}$ & 0.21 \\
\hline$\frac{1}{\sigma}$ & $0.06^{\ddagger}$ & 0.04 & $0.12^{\dagger}$ & 0.09 & $0.02^{\dagger}$ & 0.02 & $0.03^{\ddagger}$ & 0.01 \\
\hline$\xi_{p}$ & $0.88^{\dagger \dagger}$ & 0.04 & $0.79^{\dagger \dagger}$ & 0.14 & $0.81^{\dagger \dagger}$ & 0.07 & $0.61^{\dagger \dagger}$ & 0.05 \\
\hline$\pi^{*}$ & $4.16^{\dagger \dagger}$ & 1.03 & $5.92^{\dagger \dagger}$ & 1.01 & $2.43^{\dagger \dagger}$ & 0.65 & $2.38^{\dagger \dagger}$ & 0.50 \\
\hline$\lambda$ & 0.39 & 1.17 & 0.00 & - & 0.00 & - & 0.00 & - \\
\hline$\nu$ & 20.92 & 16.44 & $3.43^{\dagger}$ & 2.34 & $1.95^{\ddagger}$ & 0.95 & $2.25^{\ddagger}$ & 1.08 \\
\hline$\sigma_{g}^{2}$ & 1.68 & & 1.92 & & 0.79 & & 0.74 & \\
\hline$\sigma_{u}^{2}$ & 0.39 & & 0.69 & & 0.22 & & 0.29 & \\
\hline$\sigma_{v}^{2}$ & 1.11 & & 1.04 & & 0.29 & & 0.21 & \\
\hline $\ln L_{c}$ & -513.97 & & -205.03 & & -172.79 & & -115.80 & \\
\hline \multicolumn{9}{|c|}{$\begin{array}{l}\text { Indicates significance at } 10 \% \text { level } \\
\ddagger \text { Indicates significance at } 5 \% \text { level } \\
\dagger \text { Indicates significance at } 1 \% \text { level }\end{array}$} \\
\hline
\end{tabular}

Looking first at the policy regime parameters estimated over the full sample, a likelihood ratio test cannot reject the null hypothesis that $\lambda=0$ (p-value $=0.69$ ), confirming the result from the t-test. For the three sub-samples the non-negativity constraint on $\lambda$ tended to bind during estimation. However, for each sub-sample conventional t-tests indicate that the interest rate smoothing parameter, $\nu$, is significantly different from zero. Likelihood ratio tests of the null hypothesis that $\nu=0$ are rejected for all four estimation periods.

Turning to the remaining parameters, the estimates of the equilibrium real interest rate, $\rho^{*}$, are plausible and consistent with theory. For the pre-Volcker period, $\rho^{*}$ is estimated to be a relatively low $1.74 \%$, reflecting the productivity slowdown and the slower real GDP growth during that period. Over the Volcker-Greenspan period the estimate of $\rho^{*}$ rises to $2.37 \%$, while that for the Greenspan period is $2.34 \%$. Thus, the equilibrium real interest rate appears to have been relatively stable over 1983.Q1 2002.Q2, and to have risen slightly relative to the pre-Volcker period. The estimates of the habit formation parameter, $\gamma$, show that this parameter has been stable, and that it is precisely estimated. When $\gamma$ equals zero the consumption equation collapses 
to the standard time-separable-utility Euler equation, while a value of $\gamma$ equal to one implies that households compare current consumption to last period's consumption when allocating consumption through time. In theory, $\gamma$ must be between zero and one to ensure that household utility is increasing in steady-state consumption. While we estimate $\gamma$ to be 1.04 for the full sample, to be 1.08 for the pre-Volcker period, to be 1.02 for the Volcker-Greenspan period, and to be 1.02 over the Greenspan period, in each case $\gamma$ is insignificantly different from one. More importantly, for each sample period $\gamma$ is significantly different from zero, indicating that the standard time-seperable-in-consumption utility function provides an inadequate description of the data.

For all four sample periods, the intertemporal elasticity of substitution is found to be numerically small, suggesting that households are relatively unwilling to substitute consumption through time. One possible reason why such small substitution elasticities are obtained is that the model is estimated on GDP data rather than on consumption data and that items such as government expenditure, net-exports, and inventory growth are relatively interest rate insensitive. The estimates of $\frac{1}{\sigma}$ and $\gamma$ in Table 1 suggest that the intertemporal elasticity of substitution may not have been constant over time, declining from around 0.04 for the pre-Volcker period to 0.01 for the Greenspan period. This decline in the intertemporal elasticity of substitution appears to be driven by a change in the curvature of the utility function, $\frac{1}{\sigma}$. However, the intertemporal elasticity of substitution does appear to have been relatively stable over the Volcker-Greenspan period, with the estimate over that period (0.008) very similar to that for the Greenspan period only (0.009). Comparisons with other estimates are complicated by the fact that most other studies do not allow for habit formation. If we look, instead, at the curvature of the utility function with respect to consumption $\left(\frac{1}{\sigma}\right)$ - the parameter that other studies typically estimate - then the estimates that we obtain (0.12 for the pre-Volcker period and 0.03 for the Greenspan period) are in line with other studies. Rotemberg and Woodford (1997) estimate $\frac{1}{\sigma}$ to be 0.16 using output data (see also Campbell and Mankiw, 1989), while Kim (2000) and Ireland (1997), using consumption data, also get small and imprecisely estimated values for $\frac{1}{\sigma}$.

The Calvo-pricing parameter, $\xi_{p}$, appears to be stable up to 1987 , with very 
similar point estimates obtained for the full sample, and for the pre-Volcker period. However, it drops to 0.61 for the Greenspan period, indicating that an important change in $\xi_{p}$ has occurred, with a shift toward greater price flexibility. In each case $\xi_{p}$ is precisely estimated and lies in the interior of its permissible range. For the pre-Volcker period, $\xi_{p}$ is estimated to be 0.79 , which suggests that about 21 percent of firms re-optimize their price each quarter, but that most firms simply index their price to past inflation. For the Greenspan period, the proportion of Calvo-pricing firms rises to 39 percent, indicating that firms' pricing decision have become more sensitive to demand pressure over the more recent sample. Consistent with the results here, Galí and Gertler (1999) estimate $\xi_{p}$ to be between 0.81 and 0.92 for the period 1960.Q1 - 1997.Q4 (see their Tables 1 and 2), while Rotemberg and Woodford (1997) use a value of 0.66 to examine a data period spanning 1980 - 1995.

The Federal Reserve's implicit inflation target, $\pi^{*}$, is estimated to be $4.15 \%$ over the full sample, to be $5.92 \%$ during the pre-Volcker period, to be $2.43 \%$ during the Volcker-Greenspan period, and to be $2.38 \%$ over the Greenspan period. For each sample period the implicit inflation target is precisely estimated and the change in the implicit inflation target between the pre-Volcker period and the Volcker-Greenspan period is significantly different from zero. Furthermore, the change in $\pi^{*}$ between the two sub-samples is consistent with the view that Volcker's appointment lead to a sustained effort to bring inflation down. The results suggest that the implicit inflation target for the Greenspan period is the same as that for the Volcker-Greenspan period. These estimates of $\pi^{*}$ are qualitatively consistent with those obtained in previous studies, despite the fact that those studies have modeled households and firms as backward-looking agents (Dennis, 2001b; Favero and Rovelli, 2003). ${ }^{11}$

As shown above, the estimation results show that an output stabilization goal is not a significant factor in the Federal Reserve's objective function. Thus, while perhaps surprising in light of the literature on flexible inflation targeting (Svensson, 1997), the data do not support the view that the Federal Reserve actively pursues an output stabilization goal. Although the policy objective function that is estimated here has not been explicitly derived as a second order approximation of the households

\footnotetext{
${ }^{11}$ The sample periods that Favero and Rovelli (2003) examine are 1961.Q1 - 1979.Q2 and 1980.Q3 - 1998.Q2. To obtain their estimates of the implicit inflation target Favero and Rovelli assume that the equilibrium real interest rate equals the sample average of the ex post real interest rate.
} 
utility function, it is worthwhile noting that such approximations typically imply that the relative weight on output stabilization should be small (Amato and Laubach, 2000). While, the finding that the relative weight on output stabilization is small, or zero, challenges the conventional assumption that policymakers endeavor to stabilize both output and inflation (without making large policy interventions), it is completely consistent with the results in other studies. Favero and Rovelli (2003) estimate the relative weight on output stabilization to be 0.002 and 0.001 for the samples that they examine (see footnote 12). Similarly, Dennis (2001b) finds that the relative weight on output stabilization is insignificantly different from zero over both the preVolcker period and the Volcker-Greenspan period. ${ }^{12}$ Using calibration, Söderlind, et al. (2002) and Castelnuovo (2003) show that policy rules generated from policy regimes in which $\lambda$ is small, or zero, are better able to replicate the second moment properties of US data than are policy regimes in which $\lambda$ is large. Smaller values for $\lambda$ are more consistent with observed outcomes because, in the data, output's variability relative to that for inflation is quite high, whereas even modest values for $\lambda$ drive this variance ratio down. With a forward-looking model, and assuming precommitment to an optimized Taylor-type rule, Salemi (2001) estimates $\lambda$ to be $0.01 .^{13}$

The estimates of the relative weight on interest rate smoothing, $\nu$, are consistent with the view that Volcker's appointment led to a more aggressive and preemptive policy approach. Lower values of the interest rate smoothing parameter over the Volcker-Greenspan/Greenspan periods indicate that policymakers were more prepared to make the changes in the federal funds rate that were necessary to offset shocks, to stabilize inflation, and to bring inflation down. These point estimates are consistent with the view that the Federal Reserve smooths interest rates, perhaps due to its financial stability mandate or due to political economy considerations (Goodhart, 1997), although the importance placed on interest rate smoothing appears to have diminished over time. Dennis (2001b) obtains qualitatively similar results, but the estimates here are somewhat smaller than those that Dennis (2001b) obtains. The simulations in Castelnuovo (2003) suggest that lower estimates of $\nu$ are to be expected where private-agents are forward-looking (see also Lansing and Trehan, 2001;

\footnotetext{
${ }^{12}$ Dennis (2001b) looks at two sample periods, estimating the parameters in the US Federal Reserve's policy objective function over 1966.Q1 - 1979.Q3 and over 1982.Q1 - 2000.Q1.

${ }^{13}$ Salemi (2001) examines data spanning 1983.Q1 - 2000.Q1.
} 
Söderlind, et al. 2002) and the estimates here are consistent with that finding.

In characterizing the differences between the pre-Volcker period, the VolckerGreenspan period, and the Greenspan period, it is clear that there have been changes to both the policy regime parameters and to the households' firms' behavioral parameters. Specifically, the intertemporal elasticity of substitution is found to be smaller for the Volcker-Greenspan/Greenspan periods than it is for the pre-Volcker period, and the estimates of the Calvo-pricing parameter reveal greater price flexibility over the Greenspan period than over the pre-Volcker period. Comparing the Volcker-Greenspan estimates with the Greenspan estimates, it is clear that the only real difference lies in the value for the Calvo-pricing parameter. Even so, it is not the case that the differences in the model's structural parameters over the three subsamples necessarily lead to large changes in the reduced form equations for output and inflation. As a consequence, tests for parameter stability that are based on the reduced form equations for output and/or inflation may not detect these changes (see Rudebusch, 2002b).

Looking at the policy regime parameters, the results show that the policy regime change that occurred in the early 1980s came in the form of a reduction in the implicit inflation target and in a decline in the relative weight placed on interest rate smoothing. But, of course, economic outcomes are also affected by the shocks impacting the economy. In this regard, Table 1 illustrates that the variances of all three shocks are noticably smaller for the Volcker-Greenspan/Greenspan periods than they are for pre-Volcker period; the variances of the demand and supply shocks both more than halve. This finding that the variances of the shocks have declined over time is consistent with the results in Sims and Zha (2001).

To better illustrate the differences between the pre-Volcker period, the VolckerGreenspan period, and the Greenspan period, Figure 1 shows the dynamic responses to exogenous, one percentage point, shocks to $\rho^{*}$ and $\pi^{*}$ for each of the three periods. Figures $1 \mathrm{~A}$ and $1 \mathrm{~B}$ correspond to the pre-Volcker period, showing the responses of inflation, the output gap, and the nominal interest rate. The analogous responses for the Volcker-Greenspan period are shown in Figures $1 \mathrm{C}$ and $1 \mathrm{D}$, while those for the Greenspan period are shown in Figures 1E and 1F. Qualitatively, the responses for the three periods are similar; the underlying economic theory is of course the same. 
However, quantitatively, the responses are quite different.

Consider, first, the shock to the equilibrium real interest rate from the perspective of the theoretical model. All else constant, a one percentage point shock to the equilibrium real interest rate means that the current real interest rate is lower than the equilibrium real interest rate, giving households an incentive to shift consumption from the future to the present. With a habit formation parameter of about one, consumers raise their current consumption growth relative to expected future consumption, thus consumption rises now and consumption growth is expected to decline over time. The Calvo-pricing firms raise their output prices is response to the higher demand for their goods, which creates inflation, and the inflation-indexing firms propagate this inflation through time. With higher aggregate demand and higher inflation the central bank responds by raising nominal interest rates, thereby increasing the ex ante real interest rate. However, because of interest rate smoothing, the rise in the ex ante real interest rate is less than the rise in the equilibrium real interest rate. Consequently, in response to the shock, consumption, inflation, and the nominal interest rate all rise.

Comparing Figures $1 \mathrm{~A}$ and $1 \mathrm{C}$, because the intertemporal elasticity of substitution is larger for the pre-Volcker period than for the Volcker-Greenspan period, consumption responds more in the pre-Volcker period than in the Volcker-Greenspan period. The Calvo-pricing parameter is essentially the same, thus the greater demand response for the pre-Volcker period also translates into a larger inflation response, which in turn necessitates a larger increase in the nominal interest rate in order to stabilize the economy. As a consequence, even though policymakers place greater weight on interest rate smoothing during the pre-Volcker period, a larger policy intervention still takes place. Of course, when measured in terms of the loss function, the cost of the shock to the equilibrium real interest rate is larger for the pre-Volcker period than for the Volcker-Greenspan period. Comparing, now, the responses for the Greenspan period (Figure 1E) with those for the Volcker-Greenspan period (Figure 1C), the greater price flexibility over the Greenspan period translates into the economy returning to steady-state more quickly. 
Figure 1A - Pre-Volcker

Response to reol interest rate shock

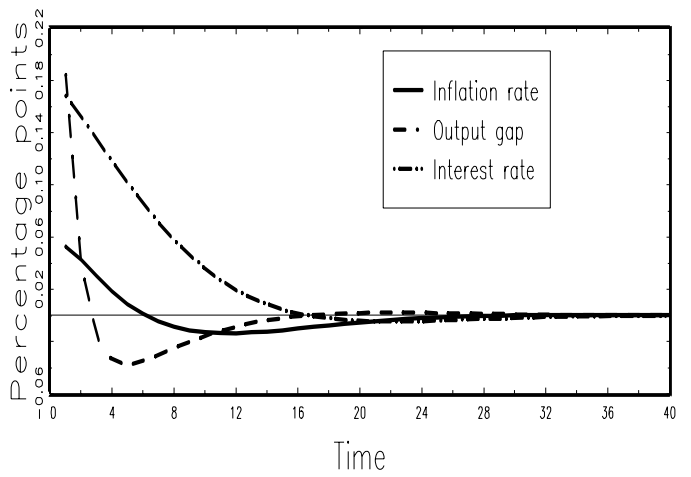

Figure $1 \mathrm{C}$ - Volcker-Greenspon

Response to real interest rate shock

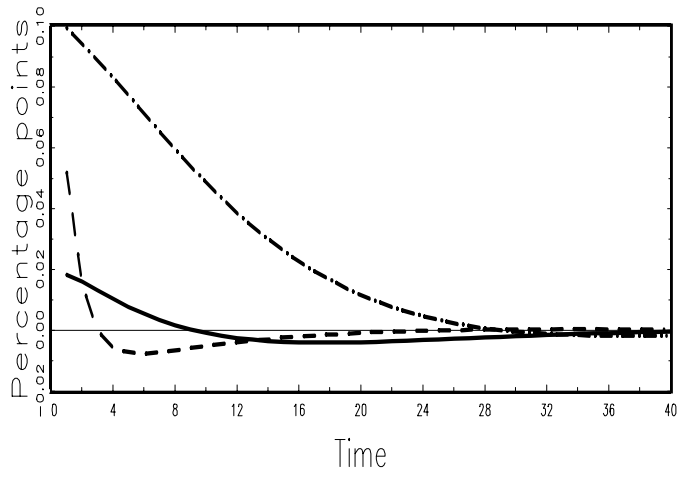

Figure 1E - Greenspan

Response to real interest rate shock

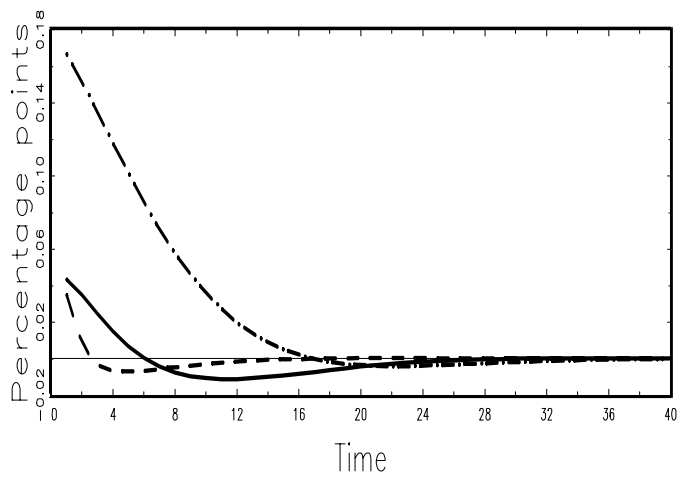

Figure 1B - Pre-Volcker

Response to inflation target shock

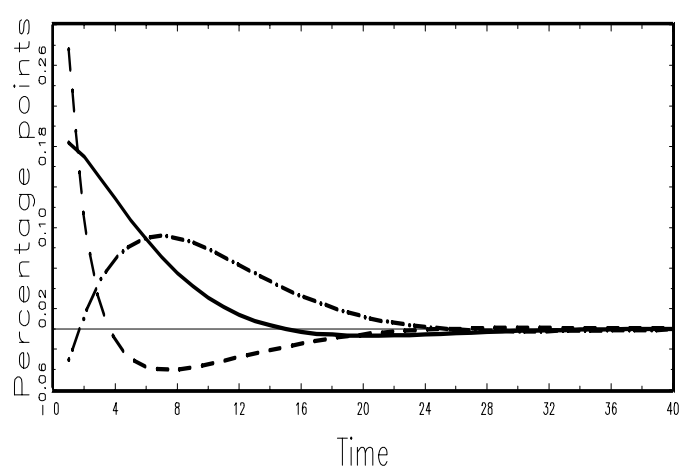

Figure 10 - Volcker-Greenspan

Response to inflation target shock

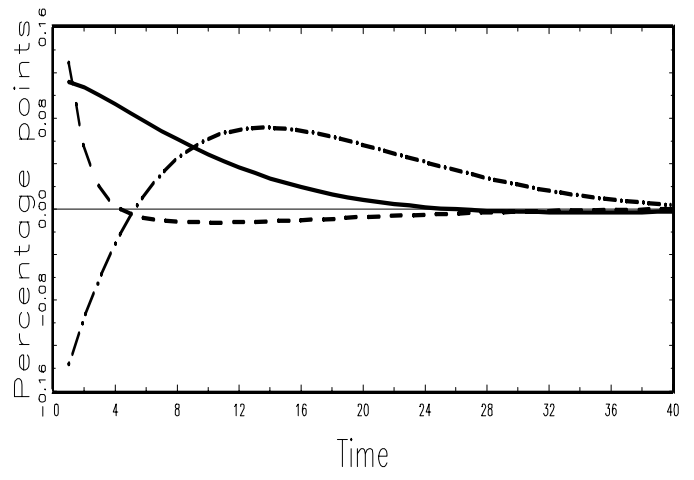

Figure $1 F$ - Greenspan

Response to inflation target shock

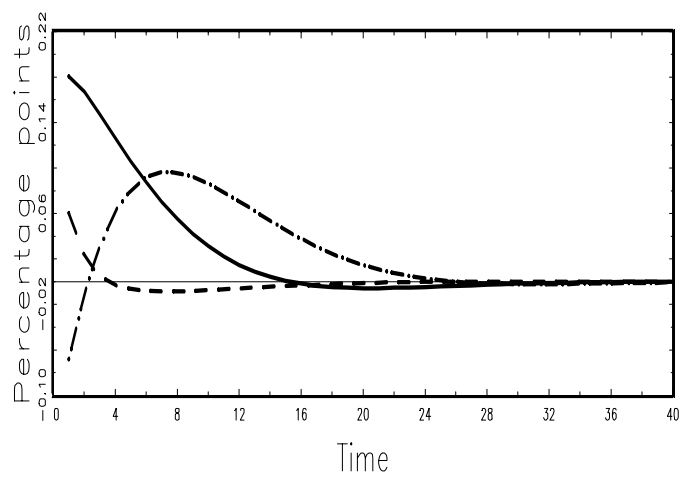

Figure 1: Impulse Response Functions

Looking now at the responses to the inflation target shock, in terms of the the- 
oretical model a rise in the implicit inflation target will create an environment in which current inflation is below the target, leading policymakers to cut interest rates. Thus, the theoretical model implies that nominal interest rates should decline, that a positive output gap will open up, and that the resulting rise in demand will lead to an increase in inflation. With the parameter estimates in Table 1, the responses of inflation for the pre-Volcker period (Figure 1B) and for the Greenspan period (Figure $1 \mathrm{~F}$ ) are roughly the same. However, for the pre-Volcker period inflation is responding to a larger output gap (due to the larger intertemporal elasticity of substitution) while for the Greenspan period inflation is more sensitive to demand pressure (due to greater price flexibility). Because the inflation responses are similar and output stabilization does not enter the policy objective function, the interest rate responses during the pre-Volcker period and the Greenspan period are also similar. The Volcker-Greenspan period shares the low intertemporal elasticity of substitution of the Greenspan period and the low price flexibility of the pre-Volcker period, which leads to lower responses in output and inflation. Nevertheless, the interest rate response is larger for the Volcker-Greenspan period than that for the pre-Volcker period because policymakers place less weight on interest rate smoothing.

\section{Conclusion}

This paper argues that it is more important and more informative to estimate a central bank's policy objective function than it is to estimate its policy reaction function. The problem with estimating policy reaction functions is that they are reduced-form equation whose coefficients are convolutions of the policymaker's targets and preferences and other model parameters. To estimate the parameters in a policymaker's objective function it is necessary to explicitly setup and solve the policymaker's optimization problem and to relate the solution to this optimization problem to the economy's evolution through time. Of course, before the parameters in the policy objective function can be estimated they must first be identified. Recognizing that identification is important, this paper derives necessary and sufficient conditions for the parameters in the optimization constraints to be identified, and given that these optimization constraints are identified, the properties of the time-consistent equilibrium are utilized to identify the parameters in the central bank's objective function. 
To estimate the policy preference parameters a maximum-likelihood-based approach that estimates jointly the policy constraints and the policy objective function is presented.

In addition to these theoretical contributions, the paper looks at monetary policy in the US, examining whether the Federal Reserve actively smooths interest rates and whether a policy regime change took place with Volcker's appointment to Federal Reserve chairman. While both of these questions have been explored previously by looking at the characteristics of estimated reduced-form policy rules, here the emphasis is upon the Federal Reserve's objective function and upon the economic structure that constrains the Federal Reserve's decision-making process. To address these questions, the paper sets up an optimization-based sticky-price New Keynesian model of the US economy and shows that the model's parameters are identified. The model is then estimated and the underlying monetary policy regime is recovered.

The results show that interest rate smoothing is an important feature in the Federal Reserve's objective function. At the same time, the relative weight placed on interest rate smoothing has not been constant over time. When Volcker was appointed Federal Reserve chairman the relative weight placed on interest rate smoothing declined, reflecting the more preemptive and activist policy approach that Volcker pursued. The relative weight assigned to interest rate smoothing during the Greenspan period is also smaller than that during the pre-Volcker period. The policy regime change that occurred with Volcker's appointment came not only in the form of a lower weight on interest rate smoothing, but also in the form of a much lower implicit inflation target.

The finding that a policy regime change occurred around the time Volcker was appointed Federal Reserve chairman is consistent with empirical studies that find that the parameters in estimated policy rules changed around this time. But, importantly, the approach taken in this paper quantifies this regime change in terms of changes to the Federal Reserve's objective function. In addition, this paper shows that behavioral parameters, such as the Calvo-pricing parameter, have not been constant over time. Specifically, there appears to be greater price flexibility during the Greenspan period than during the pre-Volcker period. There is also some evidence to suggest that the intertemporal elasticity of substitution has declined over time. 
Although changes to the household/firm behavioral parameters influence the feedback parameters in estimated policy rules, their influence is overlooked when such rules are interpreted. The estimation results also reveal that an output stabilization objective does not enter significantly into the Federal Reserve's policy objective function. While this finding may seem surprising it is consistent with previous studies, and consistent with the implications of second-order welfare approximations.

Although the model that is estimated in this paper is in some ways quite simplistic, the results are interpretable, plausible, and are in a form that allows us to explicitly test hypothesis that cannot be tested using estimated policy rules. Nevertheless, it would be desirable to extend the model along a number of dimensions. In particular, we have omitted capital accumulation, a potentially important source of endogenous dynamics, and we have not attempted to realistically model the labor market. Furthermore, we have assumed that any changes to the implicit inflation target are discrete rather than allowing the inflation target to evolve over time according to some stochastic process. Addressing these modeling issues is left for future work. A further question to be examined is how the assumption that monetary policy is set with discretion, rather than with precommitment, affects the estimation results.

\section{Appendix - Model Derivation}

The economy is populated with a constant number of households who live forever and have identical preferences over consumption, real money balances, and leisure. The representative household maximizes the utility function

$$
U(t, \infty)=E_{t} \sum_{j=0}^{\infty} \beta^{j}\left[\exp \left(g_{t+j}\right) \frac{\left(\frac{C_{t+j}}{C_{t+j-1}^{\gamma}}\right)^{1-\sigma}}{1-\sigma}+\frac{\left(\frac{M_{t+j}}{P_{t+j}}\right)^{1-\alpha}}{1-\alpha}-\frac{l_{t+j}^{1-\theta}}{1-\theta}\right],
$$

where $0<\beta<1$, subject to the intertemporal budget constraint

$$
C_{t}+\frac{M_{t+1}}{P_{t}}+\frac{B_{t+1}}{P_{t}}=\frac{W_{t}}{P_{t}} L_{t}+\frac{\left(1+I_{t}\right)}{P_{t}} B_{t}+\frac{M_{t}}{P_{t}}+\frac{\Pi_{t}}{P_{t}}
$$

This utility function exhibits internal habit formation in consumption. In equations (60) and (61), $C_{t}$ represents aggregate consumption, $M_{t}$ represents nominal money balances that are carried into period $t, P_{t}$ denotes the price level, $l_{t}$ represents leisure, $B_{t}$ denotes nominal bond holdings at the beginning of period $t$, and $\Pi_{t}$ combines together the lump-sum dividend payment that firms make to households and any lump-sum transfers from the government. The preference shock, $g_{t}$, is assumed to be a white noise process. The central bank chooses the level of the nominal interest 
rate, $I_{t}$, supplies households with whatever level of nominal money balances they demand, and remits any seignorage revenues to the government, which pays them out to households in the form of lump-sum transfers.

From the Lagrangian for the household's optimization problem, the first order conditions are

$$
\begin{aligned}
\frac{\partial L}{\partial C_{t}} & =\exp \left(g_{t}\right)\left(\frac{C_{t}}{C_{t-1}^{\gamma}}\right)^{-\sigma} \frac{1}{C_{t-1}^{\gamma}}-\gamma \beta E_{t}\left[\exp \left(g_{t+1}\right)\left(\frac{C_{t+1}}{C_{t}^{\gamma}}\right)^{-\sigma}\left(\frac{C_{t+1}}{C_{t}^{1+\gamma}}\right)\right]-\lambda_{t}( \\
\frac{\partial L}{\partial l_{t}} & =l_{t}^{-\theta}+\frac{W_{t}}{P_{t}} \lambda_{t}=0 \\
\frac{\partial L}{\partial M_{t+1}} & =\beta E_{t}\left[\left(\frac{M_{t+1}}{P_{t+1}}\right)^{-\alpha} \frac{1}{P_{t+1}}\right]+\beta E_{t}\left(\frac{\lambda_{t+1}}{P_{t+1}}\right)-\frac{\lambda_{t}}{P_{t}}=0 \\
\frac{\partial L}{\partial B_{t+1}} & =\beta\left(1+I_{t}\right) E_{t}\left(\frac{\lambda_{t+1}}{P_{t+1}}\right)-\frac{\lambda_{t}}{P_{t}}=0
\end{aligned}
$$

and the transversality conditions are $\lim _{j \rightarrow \infty} \beta^{j} \lambda_{t+j} \frac{M_{t+j}}{P_{t+j}}=0$ and $\lim _{j \rightarrow \infty} \beta^{j} \lambda_{t+j} \frac{B_{t+j}}{P_{t+j}}=0$. Here $L$ is the value of the Lagrangian and $\lambda_{t}$ is the Lagrange multiplier on the intertemporal budget constraint. Equations (65) and (62) rearrange to

$$
\begin{aligned}
\lambda_{t} & =\beta E_{t}\left[\lambda_{t+1}\left(\frac{1+I_{t}}{1+\pi_{t+1}}\right)\right] \\
\lambda_{t} & =\exp \left(g_{t}\right)\left(\frac{C_{t}}{C_{t-1}^{\gamma}}\right)^{-\sigma} \frac{1}{C_{t-1}^{\gamma}}-\gamma \beta E_{t}\left[\exp \left(g_{t+1}\right)\left(\frac{C_{t+1}}{C_{t}^{\gamma}}\right)^{-\sigma}\left(\frac{C_{t+1}}{C_{t}^{1+\gamma}}\right)\right]
\end{aligned}
$$

where $\pi_{t}$ is the period $t$ inflation rate, i.e., the percent change in the price level between $P_{t}$ and $P_{t-1}$. Log-linearizing these two Euler equations about the economy's nonstochastic steady-state, gives

$$
\begin{aligned}
& \widehat{\lambda}_{t}=E_{t} \widehat{\lambda}_{t+1}+\widehat{i}_{t}-E_{t} \widehat{\pi}_{t+1} \\
& \widehat{\lambda}_{t}=g_{t}-[\sigma+\gamma \beta(\sigma \gamma-1-\gamma)] \widehat{c}_{t}+\gamma(\sigma-1) \widehat{c}_{t-1}+\gamma \beta(\sigma-1) E_{t} \widehat{c}_{t+1},
\end{aligned}
$$

Taking a forward-difference of equation (69) and substituting in equation (68) produces equation (51) in section 5.1.

On the supply side, we follow Christiano, Eichenbaum, and Evans (2001), but simplify the model to exclude capital accumulation. Goods are produced by monopolistically competitive firms. A final goods producer takes the firms' outputs and bundles them into a single consumption good that is sold to households in a perfectly competitive market. As is widely known, the solution to the final goods producers' optimization problem yields $y_{t}^{i}=Y_{t}\left(\frac{P_{t}^{i}}{P_{t}}\right)^{-\varepsilon}$, where $y_{t}^{i}$ is the demand for the $\mathrm{i}^{\prime}$ th firms output, where $Y_{t}=\left[\int_{0}^{1}\left(y_{t}^{i}\right)^{\frac{\varepsilon-1}{\varepsilon}}\right]^{\frac{\varepsilon}{\varepsilon-1}}$ is a Dixit-Stiglitz aggregate of firms' outputs, where $P_{t}^{i}$ is the price for the i'th firms' good, and where the aggregate price level is given by $P_{t}=\left[\int_{0}^{1}\left(P_{t}^{i}\right)^{1-\varepsilon}\right]^{\frac{1}{1-\varepsilon}}$. The elasticity of substitution, $\varepsilon$, is assumed to be greater than one. From the resource constraint $C_{t}=Y_{t}$.

Following Calvo (1983), each period a fixed percentage of firms, $1-\xi_{p}$, are able to re-optimize their output price while all remaining firms are assumed to simply index 
their price change to last period's inflation rate. All firms hire labor in a perfectly competitive market, while those firms that can reset their price level also choose their output price to maximize their expected net worth. With these assumptions, the optimization problem facing a firm that can re-optimize its price is

$$
\max _{\left\{P_{t+j}^{i}\right\}_{0}^{\infty}} E_{t} \sum_{j=0}^{\infty}\left(1-\xi_{p}\right)^{j}\left[\frac{\beta^{j} \lambda_{t+j+1}}{\lambda_{t}}\left(\frac{P_{t+j}^{i}}{P_{t+j}}-s_{t+j}^{i}\right) P_{t+j} Y_{t+j}\left(\frac{P_{t+j}^{i}}{P_{t+j}}\right)^{-\varepsilon}\right],
$$

where $s_{t}^{i}$ is the i'th firm's real marginal costs in period $t$. All profits are returned to households in the form of a lump-sum dividend payment. Christiano, Eichenbaum, and Evans (2001) show that with inflation indexation the solution to the intermediategoods-producing firm's leads to the following Phillips curve

$$
\widehat{\pi}_{t}=\frac{1}{1+\beta} \widehat{\pi}_{t-1}+\frac{\beta}{1+\beta} E_{t} \widehat{\pi}_{t+1}+\frac{\left(1-\beta \xi_{p}\right)\left(1-\xi_{p}\right)}{(1+\beta) \xi_{p}} \widehat{s}_{t},
$$

which can be written in terms of the output gap as

$$
\widehat{\pi}_{t}=\frac{1}{1+\beta} \widehat{\pi}_{t-1}+\frac{\beta}{1+\beta} E_{t} \widehat{\pi}_{t+1}+\frac{\left(1-\beta \xi_{p}\right)\left(1-\xi_{p}\right)}{(1+\beta) \xi_{p}}(\sigma-\theta) \widehat{c}_{t} .
$$

In the absence of inflation indexation, the relevant Phillips curve is (see Galí and Gertler, 1999)

$$
\widehat{\pi}_{t}=\beta E_{t} \widehat{\pi}_{t+1}+\frac{\left(1-\beta \xi_{p}\right)\left(1-\xi_{p}\right)}{\xi_{p}}(\sigma-\theta) \widehat{c}_{t} .
$$

To arrive at equation (53) in section 5, we append a disturbance term, $u_{t}$, to equation (72) and assume that $\sigma-\theta=1$. In the absence of some assumption regarding $\theta$, neither $\theta$ nor $\xi_{p}$ are identified, but this assumption does not affect the estimated values of any other model parameters.

\section{References}

[1] Amato, J., and T. Laubach, (2000), "Implications of Habit Formation for Optimal Monetary Policy," Board of Governors of the Federal Reserve Working Papers in Finance and Economics \#2001-58 (May, 2001).

[2] Batini, N., and A. Haldane, (1999), "Forward-Looking Rules for Monetary Policy," in Taylor, J., (ed) Monetary Policy Rules, University of Chicago Press.

[3] Calvo, G., (1983), "Staggered Contracts in a Utility-Maximising Framework," Journal of Monetary Economics, 12, pp383-398.

[4] Campbell, J., and G. Mankiw, (1989), "Consumption, Income, and Interest Rates: Reinterpreting the Time Series Evidence," in Blanchard, O., and S. Fischer, (eds) NBER Macroeconomics Annual 1989, MIT Press, Cambridge.

[5] Castelnuovo, E., (2003), "Squeezing the Interest Rate Smoothing Weight with a Hybrid Expectations Model," FEEM Working Paper \#06-2003 (March, 2003).

[6] Chow, G., (1981), Econometric Analysis by Control Methods, Chapter 16, John Wiley and Sons, New York. 
[7] Christiano, L., Eichenbaum, M., and C. Evans, (2001), "Nominal Rigidities and the Dynamic Effects of a Shock to Monetary Policy," Northwestern University mimeo (May, 2001).

[8] Clarida, R., Galí, J., and M. Gertler, (2000), "Monetary Policy Rules and Macroeconomic Stability: Evidence and Some Theory," Quarterly Journal of Economics, 115, pp147-180.

[9] Collins, S., and P. Siklos, (2001), "Optimal Reaction Functions, Taylor's Rule and Inflation Targets: The Experiences of Dollar Bloc Countries," Wilfrid Laurier University mimeo (December, 2001).

[10] Cukierman, A., (1986), "Central Bank Behaviour and Credibility: Some Recent Theoretical Developments," Federal Reserve Bank of St. Louis Economic Review, $86, \mathrm{pp} 5-17$.

[11] Dennis, R., (2001a), "Optimal Policy in Rational Expectations Models: New Solution Algorithms," Federal Reserve Bank of San Francisco Working Paper \#2001-09 (January, 2003).

[12] Dennis, R., (2001b), "The Policy Preferences of the US Federal Reserve," Federal Reserve Bank of San Francisco Working Paper \#2001-19 (June, 2003).

[13] Dennis, R., (2003), "Solving for Optimal Simple Rules in Rational Expectations Models," Journal of Economic Dynamics and Control, forthcoming.

[14] Díaz-Giménez, J., (1999), "Linear Quadratic Approximations: An Introduction," in Marimon, R., and A. Scott, (eds), Computational methods for the Study of Dynamic Economies, Oxford University press, Oxford, United Kingdom.

[15] English, W., Nelson, W., and B. Sack, (2003), "Interpreting the Significance of the Lagged Interest Rate in Estimated Monetary Policy Rules," Contributions to Macroeconomics, 3, 1, Article 5.

[16] Favero, C., and R. Rovelli, (2003), "Macroeconomic Stability and the Preferences of the Fed. A Formal Analysis, 1961-98," Journal of Money Credit and Banking, forthcoming.

[17] Galí, J., and M. Gertler, (1999), "Inflation Dynamics: A Structural Econometric Analysis," Journal of Monetary Economics, 44, pp195-222.

[18] Goodhart, C., (1997), "Why Do the Monetary Authories Smooth Interest Rates," in Collignon, S., (ed) European Monetary Policy, London, Pinter.

[19] Hansen, L., and T. Sargent, (1980), "Formulating and Estimating Dynamic Linear Rational Expectations Models," Journal of Economic Dynamics and Control, 2, $\mathrm{pp} 7-46$.

[20] Ireland, P., (1997), "A Small, Structural, Quarterly Model for Monetary Policy Evaluation," Carnegie-Rochester Conference Series on Public Policy, 47, pp83108.

[21] Kim, J., (2000), "Constructing and Estimating a Realistic Optimizing Model of Monetary Policy," Journal of Monetary Economics, 45, pp329-359.

[22] Lansing, K., and B. Trehan, (2001), "Forward-Looking Behavior and Optimal Discretionary Monetary Policy," Economics Letters, forthcoming. 
[23] Laubach, T., and J. Williams, (2003), "Measuring the Natural Rate of Interest," Review of Economics and Statistics, forthcoming.

[24] Levin, A., Wieland, V., and J. Williams, (1999), "Robustness of Simple Monetary Policy Rules under Model Uncertainty," in Taylor, J., (ed) Monetary Policy Rules, University of Chicago Press.

[25] Lucas, R., (1976), "Econometric Policy Evaluation: A Critique," CarnegieRochester Conference Series on Public Policy, 1, pp19-46.

[26] McCallum, B., (2000), "Alternative Monetary Policy Rules: A Comparison with Historical Settings for the United States, the United Kingdom, and Japan," Federal Reserve Bank of Richmond Economic Quarterly, 86, 1, pp49-79.

[27] Pesaran, H., (1988), "Identification of Rational Expectations Models," Journal of Econometrics, 16, pp375-398.

[28] Rogoff, K., (1985), "The Optimal Degree of Commitment to an Intermediate Monetary Target," Quarterly Journal of Economics, 100, 4, pp1169-1189.

[29] Rotemberg, J., and M. Woodford, (1997), "An Optimization-Based Econometric Framework for the Evaluation of Monetary Policy," in Bernanke, B., and J. Rotemberg, (eds) NBER Macroeconomics Annual 1997, MIT Press, Cambridge.

[30] Rudebusch, G., (2002a), "Term Structure Evidence on Interest Rate Smoothing and Monetary Policy Inertia," Journal of Monetary Economics, 49, pp1161-1187.

[31] Rudebusch, G., (2002b), "Assessing the Lucas Critique in Monetary Policy Models," Federal Reserve Bank of San Francisco Working Paper \#2002-02 (June, 2002).

[32] Rudebusch, G., and L. Svensson, (1999), "Policy Rules for Inflation Targeting," in Taylor, J., (ed) Monetary Policy Rules, University of Chicago Press.

[33] Salemi, M., (1995), "Revealed Preferences of the Federal Reserve: Using Inverse Control Theory to Interpret the Policy Equation of a Vector Autoregression," Journal of Business and Economic Statistics, 13, pp419-433.

[34] Salemi, M., (2001), "Econometric Policy Evaluation and Inverse Control," University of North Carolina mimeo (December, 2001).

[35] Sims, C., and T. Zha, (2001), "Macroeconomic Switching," Princeton University mimeo (February, 2002).

[36] Söderlind, P., Söderström, U., and A. Vredin, (2002), "Can Calibrated NewKeynesian Models of Monetary Policy Fit the Facts?," Sveriges Riksbank Mimeo (January, 2002).

[37] Svensson, L., (1997), "Inflation Forecast Targeting: Implementing and Monitoring Inflation Targets," European Economic Review, 41, pp1111-1146.

[38] Taylor, J., (1993), "Discretion Versus Policy Rules in Practice," CarnegieRochester Conference Series on Public Policy, 39, pp195-214.

[39] White, H., (1982), "Maximum Likelihood Estimation of Misspecified Models," Econometrica, 50, 1, pp1-16. 